\title{
Methane on Mars and Habitability: Challenges and Responses
}

\author{
Yuk L. Yung,, ${ }^{1,2}$ Pin Chen,2 Kenneth Nealson, 3 Sushil Atreya, Patrick Beckett, Jennifer G. Blank, \\ Bethany Ehlmann, ${ }^{1,2}$ John Eiler, Giuseppe Etiope, ${ }^{7,8}$ James G. Ferry, Francois Forget, ${ }^{10}$ Peter Gao, ${ }^{11}$ \\ Renyu Hu, Armin Kleinböhl, ${ }^{2}$ Ronald Klusman, ${ }^{12}$ Franck Lefèvre, ${ }^{13}$ Charles Miller, Michael Mischna, \\ Michael Mumma, ${ }^{14}$ Sally Newman, ${ }^{1}$ Dorothy Oehler, ${ }^{15}$ Mitchio Okumura, Ronald Oremland, ${ }^{16}$ \\ Victoria Orphan, Radu Popa, ${ }^{3}$ Michael Russell, Linhan Shen, Barbara Sherwood Lollar, ${ }^{17}$ \\ Robert Staehle, Vlada Stamenković, ${ }^{1,2}$ Daniel Stolper, ${ }^{11}$ Alexis Templeton, ${ }^{18}$ Ann C. Vandaele, ${ }^{19}$ \\ Sébastien Viscardy, ${ }^{19}$ Christopher R. Webster, ${ }^{2}$ Paul O. Wennberg, Michael L. Wong, ${ }^{1}$ and John Worden ${ }^{2}$
}

\begin{abstract}
\end{abstract}
Recent measurements of methane $\left(\mathrm{CH}_{4}\right)$ by the Mars Science Laboratory (MSL) now confront us with robust data that demand interpretation. Thus far, the MSL data have revealed a baseline level of $\mathrm{CH}_{4}(\sim 0.4$ parts per billion by volume [ppbv]), with seasonal variations, as well as greatly enhanced spikes of $\mathrm{CH}_{4}$ with peak abundances of $\sim 7$ ppbv. What do these $\mathrm{CH}_{4}$ revelations with drastically different abundances and temporal signatures represent in terms of interior geochemical processes, or is martian $\mathrm{CH}_{4}$ a biosignature? Discerning how $\mathrm{CH}_{4}$ generation occurs on Mars may shed light on the potential habitability of Mars. There is no evidence of life on the surface of Mars today, but microbes might reside beneath the surface. In this case, the carbon flux represented by $\mathrm{CH}_{4}$ would serve as a link between a putative subterranean biosphere on Mars and what we can measure above the surface. Alternatively, $\mathrm{CH}_{4}$ records modern geochemical activity. Here we ask the fundamental question: how active is Mars, geochemically and/or biologically? In this article, we examine geological, geochemical, and biogeochemical processes related to our overarching question. The martian atmosphere and surface are an overwhelmingly oxidizing environment, and life requires pairing of electron donors and electron acceptors, that is, redox gradients, as an essential source of energy. Therefore, a fundamental and critical question regarding the possibility of life on Mars is, "Where can we find redox gradients as energy sources for life on Mars?" Hence, regardless of the pathway that generates $\mathrm{CH}_{4}$ on Mars, the presence of $\mathrm{CH}_{4}$, a reduced species in an oxidant-rich environment, suggests the possibility of redox gradients supporting life and habitability on Mars. Recent missions such as ExoMars Trace Gas Orbiter may provide mapping of the global distribution of $\mathrm{CH}_{4}$. To discriminate

\footnotetext{
${ }^{1}$ California Institute of Technology, Pasadena, California.

${ }^{2}$ NASA Jet Propulsion Laboratory, California Institute of Technology, Pasadena, California.

${ }^{3}$ University of Southern California, Los Angeles, California.

${ }^{4}$ University of Michigan, Ann Arbor, Michigan.

${ }^{5}$ University of California, Davis, California.

${ }^{6}$ NASA Ames Research Center, Blue Marble Space Institute of Science, Mountain View, California.

${ }^{7}$ Istituto Nazionale di Geofisica e Vulcanologia, Rome, Italy.

${ }^{8}$ Faculty of Environmental Science and Engineering, Babes-Bolyai University, Cluj-Napoca, Romania.

${ }^{9}$ The Pennsylvania State University, University Park, Pennsylvania.

${ }^{10}$ Laboratoire de Météorologie Dynamique, Institut Pierre Simon Laplace, CNRS, Paris, France.

${ }^{11}$ University of California, Berkeley, California.

${ }^{12}$ Colorado School of Mines, Golden, Colorado.

${ }^{13}$ Laboratoire Atmospheres, Milieux, Observations Spatiales (LATMOS), IPSL, Paris, France.

${ }^{14}$ NASA Goddard Space Flight Center, Greenbelt, Maryland.

${ }^{15}$ Planetary Science Institute, Tucson, Arizona.

${ }^{16}$ US Geological Survey, Menlo Park, California.

${ }^{17}$ University of Toronto, Toronto Ontario, Canada.

${ }^{18}$ University of Colorado, Boulder, Colorado.

${ }^{19}$ The Royal Belgian Institute for Space Aeronomy (BIRA-IASB), Brussels, Belgium.

(C) Yuk L. Yung et al., 2018; Published by Mary Ann Liebert, Inc. This Open Access article is distributed under the terms of the Creative Commons License (http://creativecommons.org/licenses/by/4.0), which permits unrestricted use, distribution, and reproduction in any medium, provided the original work is properly credited.
} 
between abiotic and biotic sources of $\mathrm{CH}_{4}$ on Mars, future studies should use a series of diagnostic geochemical analyses, preferably performed below the ground or at the ground/atmosphere interface, including measurements of $\mathrm{CH}_{4}$ isotopes, methane/ethane ratios, $\mathrm{H}_{2}$ gas concentration, and species such as acetic acid. Advances in the fields of Mars exploration and instrumentation will be driven, augmented, and supported by an improved understanding of atmospheric chemistry and dynamics, deep subsurface biogeochemistry, astrobiology, planetary geology, and geophysics. Future Mars exploration programs will have to expand the integration of complementary areas of expertise to generate synergistic and innovative ideas to realize breakthroughs in advancing our understanding of the potential of life and habitable conditions having existed on Mars. In this spirit, we conducted a set of interdisciplinary workshops. From this series has emerged a vision of technological, theoretical, and methodological innovations to explore the martian subsurface and to enhance spatial tracking of key volatiles, such as $\mathrm{CH}_{4}$. Key Words: Mars- $\mathrm{CH}_{4}$-Subsurface redox conditions-Mars instrumentation. Astrobiology 18, 1221-1242.

\section{Introduction}

A potential biosignature is a feature that is consistent with biological processes and that, when it is encountered, challenges the researcher to attribute it either to inanimate or to biological processes. Such detection might compel investigators to gather more data before reaching a conclusion as to the presence or absence of life. (NASA Astrobiology Roadmap, 2008, p. 15)

The scientific significance of any potential sign of past life comes not only from the probability of life having produced it, but also from the improbability of non-biological processes producing it. (Mars 2020 Science Definition Team report)

$\mathbf{M}$ ETHANE $\left(\mathrm{CH}_{4}\right)$ IS A POTENTIAL BIOSIGNATURE on Mars. Recent measurements of $\mathrm{CH}_{4}$ by the Mars Science Laboratory (MSL) have challenged the scientific community to explain the seemingly unexplainable, according to known chemical and physical processes on Mars (see Lefèvre and Forget, 2009; Yung and Chen, 2015; and discussions below). The possibility of a Mars that is biologically or geochemically active now confronts us more firmly than ever. Rising to the challenge, a group of interdisciplinary researchers conducted two workshop studies under the auspices of the Keck Institute for Space Studies. We aimed to synthesize innovative concepts for future Mars investigations focused on ascertaining the origin of methane on Mars. This article reports our recommendations in this regard. Mars offers a combination of properties of unique astrobiological importance: (1) Water/rock reactions, which can provide redox energy for life on encountering oxidants, once took place in the subsurface and on the surface of Mars and might still be taking place under the surface. (2) The general history of Mars is one of degrading habitability, such that the present martian surface is arid and ubiquitously oxidizing, inhospitable to life. (3) Of the Venus/ Earth/Mars trio, Mars is the only one presenting an observable $\sim 4$ billion-year geological record of climate and water-related processes. Thus, understanding whether life ever existed on Mars can yield unique knowledge regarding the limits of habitability. Methane provides a key clue.

There are several varieties of potential past and present sources for methane on Mars. These can be abiogenic or biogenic.

Abiogenic sources include the following:

- Reduction of $\mathrm{C}$ by $\mathrm{H}_{2}$ via Fischer-Tropsch-type (FTT) reactions (e.g., Sabatier reaction or $\mathrm{CO}_{2}$ hydrogenation), where $\mathrm{H}_{2}$ is previously produced during iron oxidation, serpentinization, and/or radiolysis.
- UV alteration (Keppler et al., 2012) of organics delivered to the planet by meteorites.

- Volcanically degassed $\mathrm{CH}_{4}$ (although this source is not an important $\mathrm{CH}_{4}$ emitter on Earth) or ancient volcanic methane stored in clathrates (Chastain and Chevrier, 2007).

- Impact metamorphism of meteoritically delivered organics (Oehler et al., 2005; Oehler and Etiope, 2017).

\section{Biogenic sources include the following:}

- $\mathrm{CH}_{4}$ produced by now extinct or extant methanogenic microorganisms.

- If life ever developed on Mars, then there probably are regions where remnant organic matter is preserved in the subsurface. Heating by, for example, impact metamorphism could enable conversion to $\mathrm{CH}_{4}$, which would then be trapped in sealed reservoirs today (Oehler et al., 2005; Oehler and Etiope, 2017).

MSL detections of $\mathrm{CH}_{4}$ and the observed temporal patterns (Webster et al., 2015; see Fig. 1a, b) now confront us with unambiguous data that demand interpretation. As discussed in Section 2, the MSL measurements of $\mathrm{CH}_{4}$ are summarized in the following observations:

(1) There is a "background" level of 0.2-0.8 parts per billion by volume (ppbv).

(2) A seasonal pattern in this low-level $\mathrm{CH}_{4}$ is emerging from the set of year-over-year measurements to date (Webster et al., 2018).

(3) Three spikes of $\mathrm{CH}_{4}$ with peak values of $6-10 \mathrm{ppbv}$ have been observed.

These observations pose fundamental challenges to our current understanding of Mars. First, according to known atmospheric chemistry, the gas-phase lifetime of $\mathrm{CH}_{4}$ is about 300 years (Summers et al., 2002; Atreya et al., 2007). Given this predicted photochemical lifetime, which is far longer than global atmospheric mixing timescales on Mars, a small source based on photolytically driven release of $\mathrm{CH}_{4}$ from interplanetary dust particles may be sufficient to explain the background observation (observation 1) (Webster et al., 2015). However, the long lifetime of $\mathrm{CH}_{4}$ is incompatible with the observed variability (observation 2) (Lefèvre and Forget, 2009). This suggests that hitherto unknown physical and/or chemical processes are controlling the variability of atmospheric $\mathrm{CH}_{4}$. The spikes of $\mathrm{CH}_{4}$ (observation 3 ) suggest the possibility of deeper connections 
FIG. 1. Summary of TLS measurements of $\mathrm{CH}_{4}$, both (a) including and (b) excluding the high spike data from year 1 (ca. January 2014). Data from Webster et al. (2015, 2018). TLS, Tunable Laser Spectrometer.
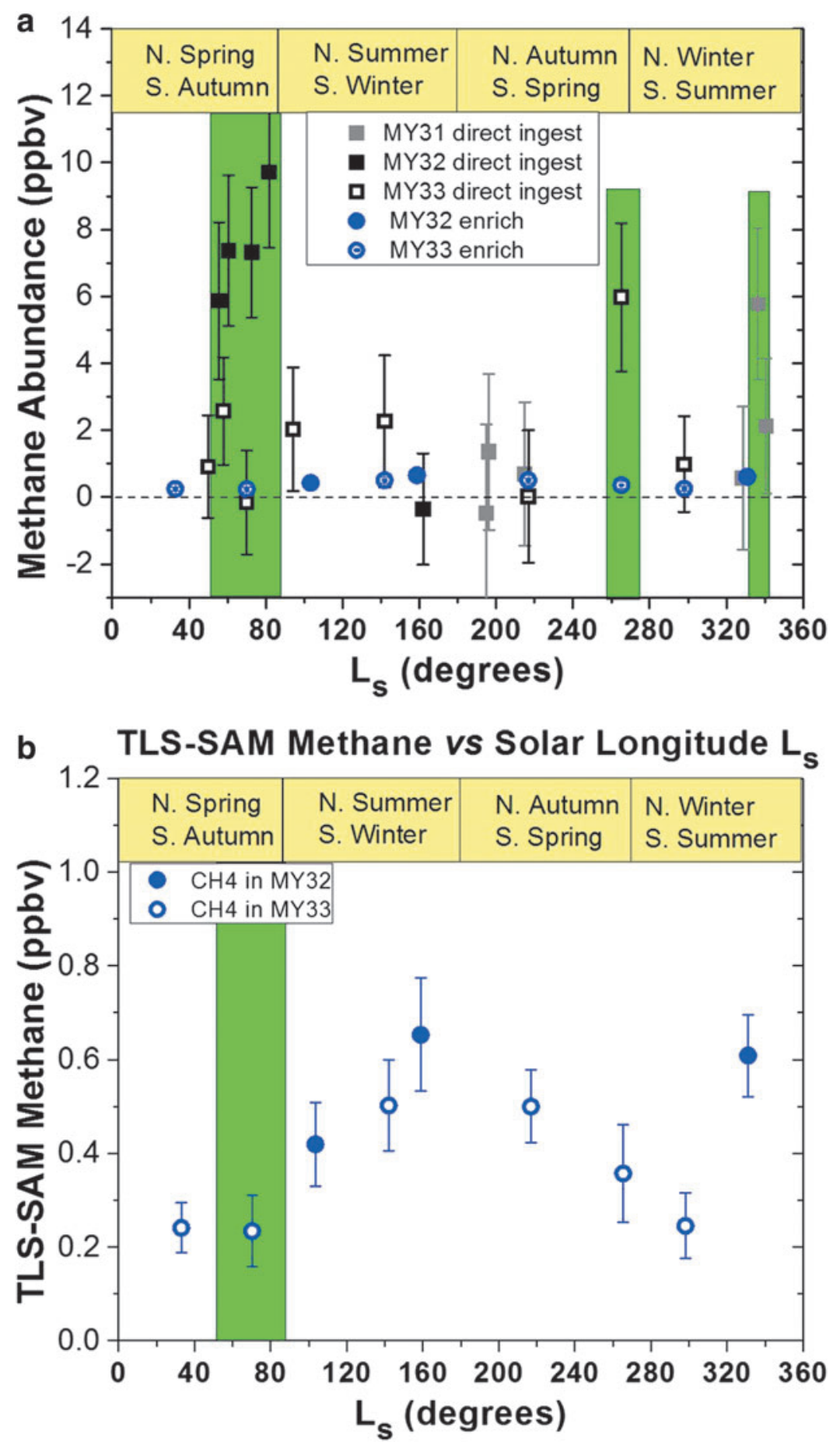

to martian geology, geophysics, geochemistry, and possibly biogeochemistry and astrobiology.

We address these questions in nine sections. Sections 2 through 5 address the fundamental question: How active is Mars geophysically and/or biologically? Section 2 discusses MSL measurements. Section 3 details the physical and chemical processes related to the lifetime of $\mathrm{CH}_{4}$. Section 4 addresses the possible geophysical, geochemical, and biogeochemical processes associated with $\mathrm{CH}_{4}$. Section 5 addresses issues related to seepage and measurement strategies. The three subsequent sections focus on the next steps in Mars $\mathrm{CH}_{4}$ sci- ence. ExoMars Trace Gas Orbiter (TGO) is expected to provide the next leap in our knowledge of methane on Mars, as discussed in Section 6, followed by a discussion in Section 7 of biosignatures and exploration of the martian subsurface. The subsurface is expected to play a major role in the search for biosignatures because it is the only place to find reductants on Mars (the surface is universally too oxidizing) and because of the potential for biopreservation. To take advantage of these expected and potential new measurements, it is essential that we develop appropriate modeling capabilities, especially related to the transport of trace species, and innovative 
technologies; this aspect is discussed in Section 8. Finally, Section 9 discusses our conclusions and a vision for the future exploration of Mars.

\section{MSL Measurements}

In this article, we focus on the MSL Tunable Laser Spectrometer (TLS) measurements. Previous measurements are summarized in Appendix 1. These prior remote-sensing detection claims have been questioned due to interference from telluric absorption in the ground-based observations, low spectral resolution in the orbital observations, and contradictions between the locations of maxima reported in groundbased observations compared to maps created from spacecraft data. A way to move forward is suggested in Appendix 1.

MSL's measurements indicate a background $\mathrm{CH}_{4}$ mixing ratio of $0.2-0.8 \mathrm{ppbv}$ and three spikes that are an order of magnitude larger (Webster et al., 2015, see Fig. 1a, b for details). These findings suggest that at least two types of $\mathrm{CH}_{4}$ emission are at work: a constant emission responsible for the background level and a mechanism for producing spikes. This discovery may come to be seen as one of the "Eureka moments" of the first half-century of robotic exploration of Mars, which began with the first success of the US spacecraft Mariner 4 in 1965. These intriguing findings compel a new era of Mars and astrobiological research to explain the existence and variability of $\mathrm{CH}_{4}$ in the martian atmosphere.

The TLS instrument in the Sample Analysis at Mars suite on the Curiosity rover has been making measurements for 3 years of the near-surface atmosphere of Mars at Gale crater. The TLS uses an infrared laser with a wavelength of $3.27 \mu \mathrm{m}$ to scan over the $\mathrm{R}(3)$ spectral lines at ultrahigh spectral resolution. This is done in two measurement modes: a direct ingest with a typical uncertainty of $2 \mathrm{ppbv}$ and an enriched method with a typical uncertainty of $\sim 0.1 \mathrm{ppbv}$, achieved by scrubbing out carbon dioxide during a slow fill of the sample cell.

In early measurements using only the direct ingest method, $\mathrm{CH}_{4}$ amounts were typically $\sim 1$ ppbv (Webster et al., 2013), except during a 2-month period when, for four sequential measurements, high mixing ratios of around $7 \mathrm{ppbv}$ were observed, only to subsequently, and suddenly, disappear. This spike of high $\mathrm{CH}_{4}$ (Webster et al., 2015), observed in northern hemisphere springtime, was attributed to a small local source. Daytime/nighttime differences in wind fields indicated a source to the north, most likely inside Gale crater. One Mars year later, the high values did not return, and a seasonal effect on the $10 \times$ enhancement was therefore ruled out. A recent study of the $\mathrm{CH}_{4}$ observations from a variety of sources, including Curiosity, concluded that a cometary source of the $\mathrm{CH}_{4}$ (Kress and McKay, 2004; Fries et al., 2016) was highly unlikely (Roos-Serote et al., 2016).

Using the $\mathrm{CH}_{4}$ enrichment method, which provides sensitivity 23 times that of the direct ingest technique and typical uncertainties of $0.1-0.2 \mathrm{ppbv}$, the "background" low levels have been studied for nearly two consecutive martian years. Measurements thus far reveal an intriguing seasonal behavior (with the mixing ratio ranging from 0.2 to $0.8 \mathrm{ppbv}$; see Fig. 1b) that appears to correlate not with pressure, but with UV radiation. Models using expected amounts of infalling meteoric material and interplanetary dust, with a specified organic content and $\mathrm{UV} \mathrm{CH}_{4}$ production efficiency, predict mean background levels of about $2.5 \mathrm{ppbv}$, some five times larger than that observed by TLS. Also, the magnitude of the range of TLS observations - from 0.2 to $0.8 \mathrm{ppbv-is}$ much larger than that predicted for $\mathrm{CH}_{4}$ assuming its currently accepted long lifetime of $\sim 300$ years, which far exceeds the global atmospheric mixing time of a few weeks to 1 month. Therefore, the TLS background measurements also imply that unknown loss (and source) processes are at work. Heterogeneous chemistry involving martian dust is a candidate that will be explored in laboratory studies.

\section{Lifetime of $\mathrm{CH}_{4}$}

Both the variability of the $\mathrm{CH}_{4}$ background and the spikes hint at a rather short lifetime of about one martian season, which conflicts with the atmospheric lifetime estimated using known gas-phase chemistry, summarized as follows.

The primary fate of $\mathrm{CH}_{4}$ on Mars is oxidation to $\mathrm{CO}_{2}$ and $\mathrm{H}_{2} \mathrm{O}$ :

$$
\begin{gathered}
\mathrm{CH}_{4}+\mathrm{OH} \rightarrow \mathrm{CH}_{3}+\mathrm{H}_{2} \mathrm{O} \\
\mathrm{CH}_{3}+\mathrm{O}_{2}+\mathrm{M} \rightarrow \mathrm{CH}_{3} \mathrm{O}_{2}+\mathrm{M} \\
\mathrm{CH}_{3} \mathrm{O}_{2}+\mathrm{HO}_{2} \rightarrow \mathrm{CH}_{3} \mathrm{OOH}+\mathrm{O}_{2} \\
\mathrm{CH}_{3} \mathrm{OOH}+h v \rightarrow \mathrm{CH}_{3} \mathrm{O}+\mathrm{OH} \\
\mathrm{CH}_{3} \mathrm{O}+\mathrm{O} \rightarrow \mathrm{H}_{2} \mathrm{CO}+\mathrm{OH} \\
\mathrm{H}_{2} \mathrm{CO}+h v \rightarrow \mathrm{H}_{2}+\mathrm{CO} \\
\mathrm{CO}+\mathrm{OH} \rightarrow \mathrm{CO}_{2}+\mathrm{H} \\
\mathrm{H}+\mathrm{O}_{2}+\mathrm{M} \rightarrow \mathrm{HO}_{2}+\mathrm{M} \\
\text { Net: } \mathrm{CH}_{4}+\mathrm{O}_{2}+\mathrm{O} \rightarrow \mathrm{CO}_{2}+\mathrm{H}_{2} \mathrm{O}+\mathrm{H}_{2} .
\end{gathered}
$$

where $\mathrm{M}$ represents a third body (primarily $\mathrm{CO}_{2}$ ) in the ambient atmosphere.

The first reaction listed in the above oxidation scheme has a high activation energy, resulting in a long gas-phase lifetime of $\sim 300$ years for $\mathrm{CH}_{4}$ (Summers et al., 2002; Atreya et al., 2007). For a discussion of this chemistry, which is well known in the terrestrial atmosphere, the reader is referred to Chapter 10 of Yung and DeMore (1999) and to Fig. 2a from Hu et al. (2012), based on the classic work of McElroy and Donahue (1972). To explain the rapid changes in $\mathrm{CH}_{4}$, as reported by Webster et al. (2015), the lifetime has to be shorter than 1 year (Lefèvre and Forget, 2009), which is incompatible with the standard working models of the chemistry of the martian atmosphere (Nair et al., 1994; Chapter 7 of Yung and DeMore, 1999; Yung et al., 2010). Nonstandard chemistry such as an enhanced source of $\mathrm{H}_{2} \mathrm{O}_{2}$, proposed by Atreya et al. (2007), is unlikely because the hypothetical oxidants will also oxidize $\mathrm{CO}$ and $\mathrm{H}_{2}$ in the martian atmosphere, and there is currently no evidence for additional destruction mechanisms for these species.

A potential explanation for the observed seasonal variability of $\mathrm{CH}_{4}$ on Mars, without altering the basic atmospheric chemistry, is physical and chemical sequestration in the soil (Gough et al., 2011; Jensen et al., 2014; Hu et al., 
FIG. 2. (a) Mixing ratios of minor species in the atmosphere of Mars (Hu et al., 2012). (b) Simulation of $\mathrm{CH}_{4}$ with a source of $75,000 \mathrm{t} /$ year at the Martz crater at $L_{\mathrm{s}}=80^{\circ}$ and a lifetime of 1 month. Based on a model by Lefèvre and Forget (2009).

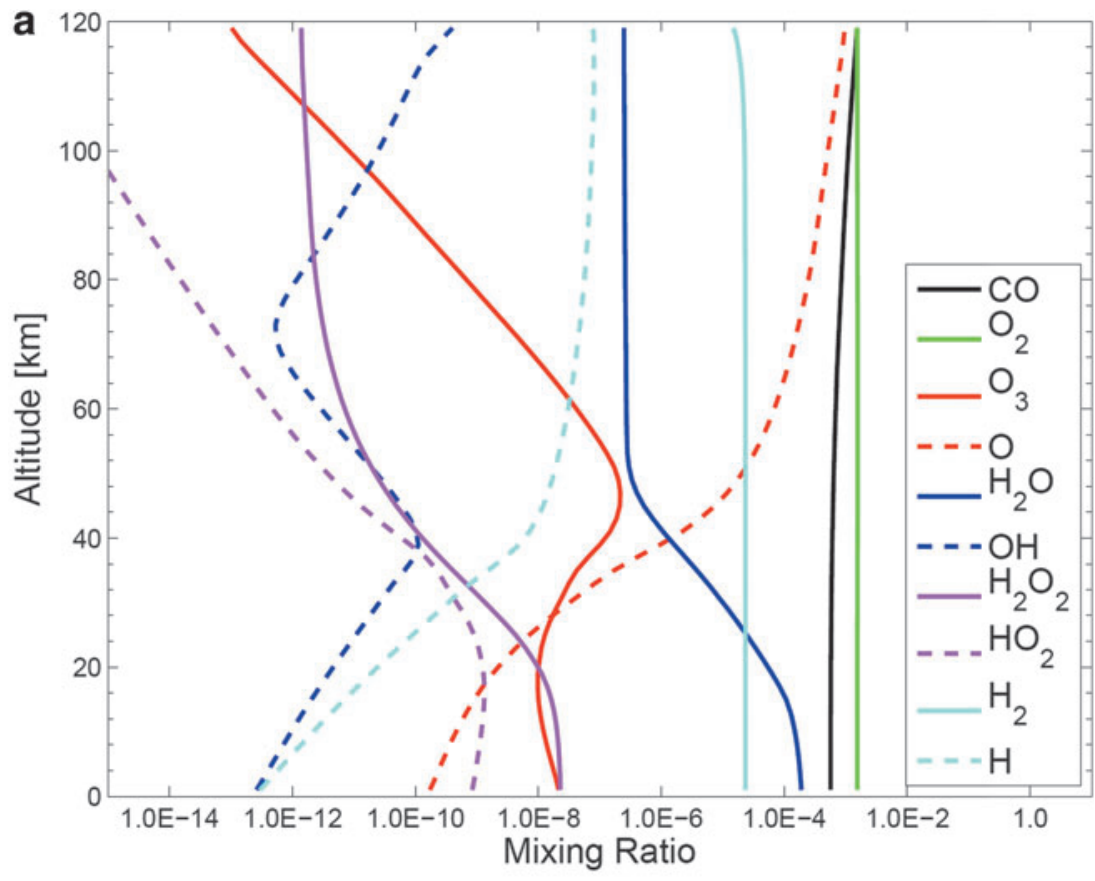

b

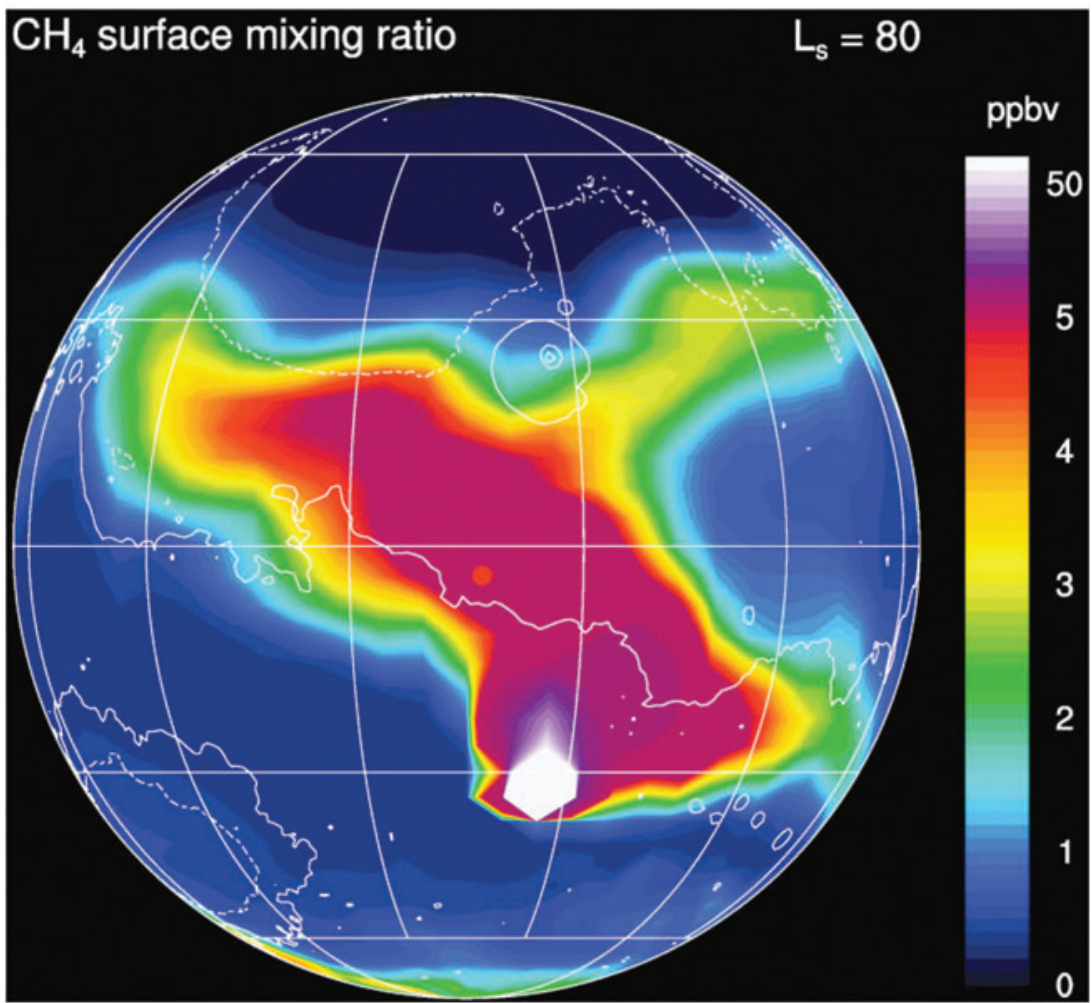

2016). In this case, the $\mathrm{CH}_{4}$ from the atmosphere is temporarily stored in the soil and later released to the atmosphere. This scenario produces a short lifetime for $\mathrm{CH}_{4}$ without actually destroying it. Presumably, seasonality should be inherent in such a process. Hence, such mechanisms might explain the background methane, but they cannot account for the methane spikes. According to Jensen et al. (2014), $\mathrm{CH}_{4}$ is removed when silicate grains form covalent bonds with $\mathrm{CH}_{4}$ via the following reaction:

$$
\mathrm{Si}+\mathrm{CH}_{4} \rightarrow \mathrm{Si}-\mathrm{CH}_{3}+\mathrm{H}
$$

Nuclear magnetic resonance analysis indicated the formation of $\mathrm{Si}-\mathrm{CH}_{3}$ bonds, which remain intact to at least $250^{\circ} \mathrm{C}$ (Jensen et al., 2014).

The reverse reaction, releasing $\mathrm{CH}_{4}$ back to the atmosphere, has not been studied in the laboratory. However, we envision reactions such as the following: 


$$
\begin{gathered}
\mathrm{Si}-\mathrm{CH}_{3}+\mathrm{H} \rightarrow \mathrm{Si}+\mathrm{CH}_{4} \\
\mathrm{Si}-\mathrm{CH}_{3}+\mathrm{HO}_{2} \rightarrow \mathrm{Si}+\mathrm{CH}_{4}+\mathrm{O}_{2},
\end{gathered}
$$

where the $\mathrm{H}$ and $\mathrm{HO}_{2}$ radicals are readily available on Mars from the photolysis of $\mathrm{H}_{2} \mathrm{O}$ and subsequent reactions:

$$
\begin{gathered}
\mathrm{H}_{2} \mathrm{O}+h v \rightarrow \mathrm{H}+\mathrm{OH} \\
\mathrm{H}+\mathrm{O}_{2}+\mathrm{M} \rightarrow \mathrm{HO}_{2}+\mathrm{M} \\
\mathrm{O}+\mathrm{OH} \rightarrow \mathrm{O}_{2}+\mathrm{H},
\end{gathered}
$$

From a standard photochemical model of Mars, we can estimate the concentrations of $\mathrm{H}$ and $\mathrm{HO}_{2}$ at the surface of Mars to be as follows:

$$
\begin{gathered}
{[\mathrm{H}] \sim 10^{4} \mathrm{~cm}^{-3}} \\
{\left[\mathrm{HO}_{2}\right] \sim 10^{7} \mathrm{~cm}^{-3}}
\end{gathered}
$$

We should point out that heterogeneous reactions (reactions between gas and solid reactants) have been proposed for Mars on the basis of laboratory studies (Anbar et al., 1993).

Dynamical transport provides another indicator of the lifetime of $\mathrm{CH}_{4}$. Lefèvre performed dynamical simulations based on the model of Lefèvre and Forget (2009) to investigate 10 individual $\mathrm{CH}_{4}$ source locations (Apollinaris Patera, Gale crater, Elysium Mons, Lybia Montes, Martz crater, Medusae Fossae, Nier crater, Nili Fossae, Orcus Patera, and Tyrrhena Patera) over a range of source strengths and atmospheric lifetimes. As expected, scenarios involving 300-year lifetimes were far from compatible with the observed temporal pattern. Approximating the $\sim 7 \mathrm{ppbv}$ TLS-observed spike required a lifetime of 1 month with a source strength of $75,000 \mathrm{t} /$ year of $\mathrm{CH}_{4}\left(5 \times 10^{9} \mathrm{~mol} / \mathrm{year}\right)$ (Fig. 2b). For example, the regolith in Gale crater could adsorb methane when dry and release this methane to the atmosphere if deliquescence or a thin film of water/rock reactions occurs. A large but not prohibitive adsorption coefficient is required in this mechanism.

\section{Geology and Geochemistry Relevant to Life on Mars}

How life might emerge on a terrestrial planet such as Mars is far from settled. There are a multitude of ideas, each with their own intriguing pros and unresolved cons. They have quite a broad range: from the "primordial soup" hypothesis, encouraged by prebiotic chemistry experiments simulating a wet reducing atmosphere shocked by lightning (Miller, 1953), to the "clay life" hypothesis, which posits that life began as self-replicating minerals (Cairns-Smith and Hartman, 1986; Hartman, 1998), to the submarine alkaline hydrothermal vent theory (Russell and Hall, 1997), and to the "global chemical reactor" hypothesis, an intriguingly holistic approach that calls on contributions from nearly every aspect of a terrestrial planet (Stüeken et al., 2013). In a comprehensive treatise, "The Origin and Nature of Life on Earth: The Emergence of the Fourth Geosphere," Smith and Morowitz (2016) argue that the emergence of life followed a path of least resistance along the "long arc of planetary disequilibrium," involving the atmosphere, oceans, and a dynamic mantle.

Metabolic processes that generate $\mathrm{CH}_{4}$ share certain similarities with - and, indeed, may have heritage in - certain abiotic geochemical pathways. Thus, for the purpose of this study, we consider life through the lens of its metabolic properties in the context of a planetary redox system. Our current knowledge indicates the following general characteristics of life: (1) it utilizes either photons or reduced compounds to drive redox reactions (involving oxidants such as perchlorate, sulfate, nitrate, and ferric iron) that fuel life's processes (Marlow et al., 2014; Luo et al., 2015); (2) it involves disequilibrium (free energy) conversions, much of them across cellular membranes and especially involving redox gradients (Shock, 1992; Russell and Hall, 1997); (3) it exploits Brownian motion, limiting its operations to $-20^{\circ} \mathrm{C}$ and $120^{\circ} \mathrm{C}$ (Rivkina et al., 2000; Takai et al., 2008; Branscomb et al., 2017); (4) it involves multiple feedbacks; and (5) it generates a myriad of mineral types beyond those of the initial geochemical inventory (Hazen et al., 2008). Given these terms of reference, it behooves us to attempt to understand the still disputed initial redox states of Mars. $\mathrm{H}_{2}$, and possibly $\mathrm{CH}_{4}$, would have comprised a portion of the volatile flux from what was once a planet with low oxygen and high $\mathrm{H}_{2}$ fugacities (McSween et al., 2009; McSween and Huss, 2010). However, did Mars always have a $\mathrm{CO}_{2}$ atmosphere? According to Gaillard and Scaillet (2014), magmatic degassing on Mars might have favored $\mathrm{CO}$ rather than $\mathrm{CO}_{2}$ as the dominant gas (Fig. 3). How did the atmosphere evolve, then, to its present condition, and over what pressures did it do so $(\mathrm{Hu}$ et al., 2015; Ehlmann et al., 2016)? Gaillard and Scaillet (2014) suggest that the composition of gases outgassed on Earth might have been significantly different from that on Mars (Fig. 3).

Two processes involving the transformation of electrochemical energies through charge separation (across a membrane) constitute the fundamental sources of free energy fueling all known life; these are oxidative phosphorylation and electron bifurcation (Mitchell, 1975; Xia et al., 2007; Schoepp-Cothenet et al., 2012; Lubner et al., 2017). In this respect, the planet acts as a battery providing electrical power, and a biological cell is analogous to a hydrogen burning fuel cell (Mitchell, 1967). The insides of prokaryote cells are also crowded and well structured, consisting of relatively electron-rich organic molecules that render them slightly alkaline, whereas their exteriors are generally more oxidized and acidic (Ellis, 2001; Lane, 2017). Thus, aqueous geochemistry in the former and biochemistry in the latter are both of a proton motive nature (Harold, 2001; Martin and Russell, 2007; Russell, 2007). The particular prokaryotic process that reduces carbon dioxide to $\mathrm{CH}_{4}$ is achieved by the methanogenic archaea. The abiotic pathway discussed in the next paragraph has to overcome thermodynamic barriers (comprising the two intermediates: formate, $\mathrm{HCOO}^{-}$, and formaldehyde, $\mathrm{HCHO}$ ) and therefore prohibitively slow in the absence of catalysts (Fig. 4). For both the biotic and abiotic processes, the reaction rolls downhill in energy after formaldehyde formation, progressing toward a methyl group and thence to the stable $\mathrm{CH}_{4}$ molecule, away from the back reaction to formate and $\mathrm{CO}_{2}$ (Fig. 4). In other words, the hydrogenation reactions are "pulled" toward $\mathrm{CH}_{4}$ in a 
FIG. 3. Global chemical trends of basalt degassing at pressures ranging from 1000 to $10^{-6}$ bar, encompassing subaerial venting conditions expected to prevail on telluric bodies. The total volatile abundances in the basalt are $600 \mathrm{ppm} \mathrm{CO}_{2}$, 1000 ppm $\mathrm{H}_{2} \mathrm{O}, 1000 \mathrm{ppm}$ S. Taken from Gaillard and Scaillet (2014).

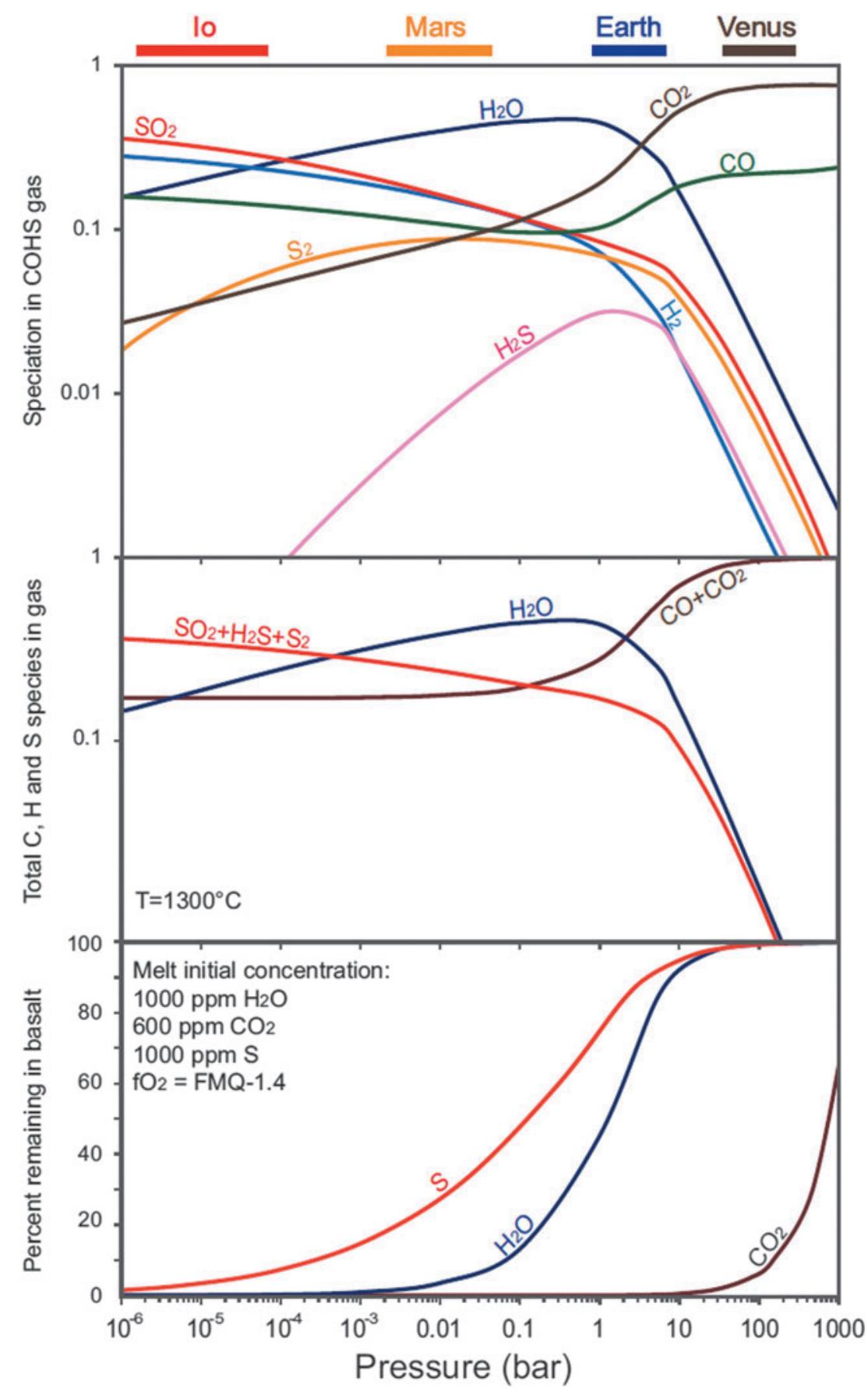

process that can be likened geochemically to siphoning (Russell and Hall, 2009). The biological pathway facilitates the process by way of the acetyl coenzyme A pathway, the most ancient of biochemical pathways (Fuchs, 1989). In this case, the same kinetic impediments to methanogenesis are cleared, although much more rapidly, with the energy provided by the proton motive force (Fig. 4).

Geochemical (abiotic) processes, generally known as FTT reactions, utilize $\mathrm{H}_{2}$ produced by serpentinization or other sources, such as the radiolysis of water (Sherwood Lollar et al., 2014), and magma degassing under reducing conditions to reduce $\mathrm{CO}_{2}$. The breakdown of iron-bearing primary minerals, such as olivine in the serpentinization process, allows electrons to be transferred from ferrous iron to $\mathrm{H}_{2}$ as ferrous iron is oxidized to form magnetite (Abrajano et al., 1990; McCollom and Bach, 2009; Holm et al., 2015; McCollom and Donaldson, 2016).

$$
\begin{aligned}
& 6 \mathrm{Mg}_{1.5} \mathrm{Fe}_{0.5} \mathrm{SiO}_{4}+7 \mathrm{H}_{2} \mathrm{O} \rightarrow 3 \mathrm{Mg}_{3} \mathrm{Si}_{2} \mathrm{O}_{5}(\mathrm{OH})_{4}+\mathrm{Fe}_{3} \mathrm{O}_{4}+\mathrm{H}_{2} \\
& \text { olivine serpentine magnetite }
\end{aligned}
$$

In a second, separate step, an FTT reaction can take place through which $\mathrm{H}_{2}$ reduces carbon dioxide to $\mathrm{CH}_{4}$. Thus, given a source of $\mathrm{CO}_{2}$ and $\mathrm{H}_{2}$, as we have seen, it is possible to form $\mathrm{CH}_{4} \cdot \mathrm{CH}_{4}$ production is possible and relatively 


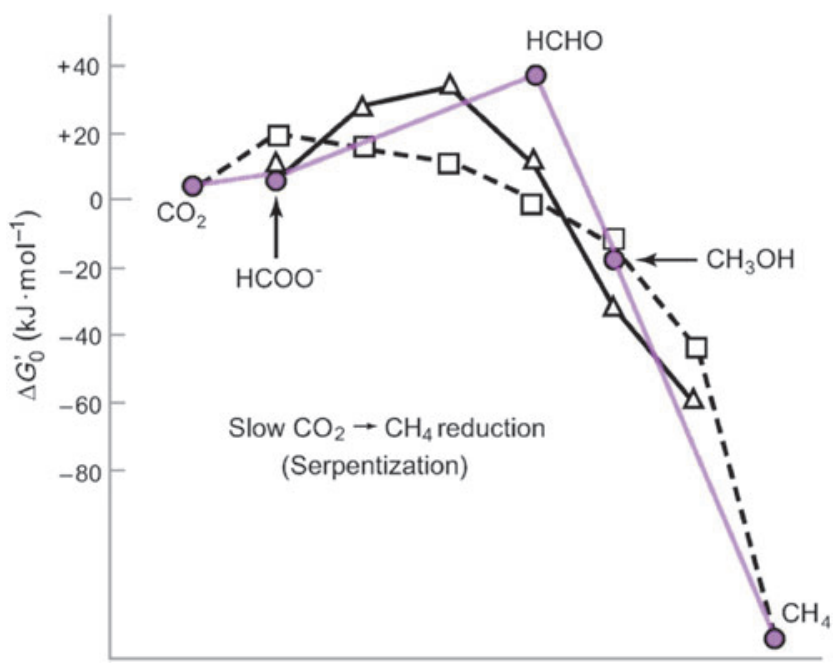

FIG. 4. Free-energy profile of a hydrothermal pathway (in purple) to methane (Seewald et al., 2006) is contrasted with the reduction profiles of the acetogenic bacteria (triangles) and methanogenic archaea (squares); both biological mechanisms use the acetyl coenzyme-A pathway. We can think of the geochemical pathway as a chemical siphon while the much more rapid biochemical pathways are driven by chemiosmosis over the intermediates formate and formaldehyde (or the formyl group). Adapted from Maden (2000).

rapid, even at low temperatures, via gas-phase FTT reactions (both $\mathrm{CO}_{2}$ and $\mathrm{H}_{2}$ in the gaseous phase, e.g., in dry or unsaturated rocks), in the presence of metal catalysts (heterogeneous catalysis; Etiope and Ionescu, 2015).

$$
\mathrm{CO}_{2}+4 \mathrm{H}_{2} \rightarrow \mathrm{CH}_{4}+2 \mathrm{H}_{2} \mathrm{O}
$$

FTT reaction is feasible only in dry, gas-phase conditions, because dissolved phases of $\mathrm{CO}_{2}$ and $\mathrm{H}_{2}$ are not chemisorbed on the metal catalyst and the reaction does not proceed toward $\mathrm{CH}_{4}$ and $\mathrm{H}_{2} \mathrm{O}$. This implies that $\mathrm{CH}_{4}$, an electron donor for prebiotic chemistry, can be obtained in the absence of water. This can occur in rocks particularly enriched with metals that can act as Sabatier catalysts, such as chromium- and ruthenium-enriched chromitites, for example, the Chassigny meteorites, which likely occur in several regions of Mars (Oehler and Etiope, 2017). After $\mathrm{CH}_{4}$ is generated, it may migrate toward rocks containing water, where biological processes can operate.

Aside from redox conditions enabling $\mathrm{CO}_{2}$ hydrogenation, we must also ask if early Mars was habitable with respect to the presence of liquid water. An Earth-like environment with open oceans is probably unlikely. Instead, we envision a colder, more arid atmosphere/hydrosphere with episodes of surface water (Ehlmann et al., 2011). Driven by obliquity cycling and early loss of water to space, arid conditions and episodically icy highlands may have been the norm (Lammer et al., 2013; Wordsworth, 2016). Emergence of life under icy conditions could be possible (Russell et al., 2014). More clement episodes might occur during periods of enhanced volcanism or glaciation/deglaciation cycles resulting from climate feedbacks (Batalha et al., 2016; Kite et al., 2017). Lakes certainly existed for intervals of thousands of years (Grotzinger et al., 2014,
2015), and mineralogical evidence points to persistent, longlived groundwater reservoirs, while surface waters were more episodic (Ehlmann et al., 2011). In the Gale crater region, the ancient aqueous environment was characterized by neutral $\mathrm{pH}$, low salinity, and variable redox states of both iron and sulfur species, and key biogenic elements - carbon, hydrogen, oxygen, sulfur, nitrogen, and phosphorus-were measured. Deuterium/hydrogen isotope ratios from ancient clays in a Gale lake deposit (Mahaffy et al., 2015) indicate that a global equivalent layer of water of 100 to $150 \mathrm{~m}$ in depth was present at the time of sediment accumulation (Grotzinger et al., 2015). Hydrogen gas production was enabled by diagenetic, groundwater reactions to form magnetite and saponite from olivine (Bristow et al., 2015). Under these circumstances, life could have emerged.

If life did emerge on Mars, there are at least two reasons for it to have gone underground and use chemical reactions from $\mathrm{H}_{2}$ and $\mathrm{CH}_{4}$ for energy. First, the loss of a thicker early Mars atmosphere may have led to the loss of its associated greenhouse effect, resulting in a colder, more arid and more radiation-exposed surface (Hu et al., 2015). Second, the loss of $\mathrm{H}_{2}$ by escape from the top of the atmosphere may have left behind an increasingly oxidized surface environment. Early methanogens on Mars, which might have emerged in the early, more reducing environment, would have migrated to the subsurface in ways similar to the migration of terrestrial anaerobes to the "deep biosphere." Methanogens and methanotrophs could exist today if the subsurface of Mars had water, which some speculate (Grimm et al., 2017).

\section{Detection of $\mathrm{CH}_{4}$ Seepage}

It is widely accepted that the occurrence of $\mathrm{CH}_{4}$ in the martian atmosphere may imply the presence of active geological sources, that is, gas emission structures in the martian soil and subsoil. In other words, gas seepage, a process well known on Earth, should exist on Mars. An extensive literature exists on terrestrial seepage; definitions, geological and geochemical processes, implications, and a literature review are summarized in Etiope (2015). We also refer the reader to Oehler and Etiope (2017) for a recent review of processes that can possibly generate methane seepage on Mars and identification/detection methods. The following is a brief summary of some relevant points.

Seepage on Mars can be revealed in specific surface manifestations in association with faults and fractured rocks, analogous to those observed on Earth. Gas seepage structures may include small circular depressions along faults, polygonal fractures, mounds, and mud volcanoes. Similar geological structures have already been observed in many areas on Mars (Oehler and Allen, 2010; Etiope et al., 2011b, 2013), but their actual gas-bearing role is unknown (Wray and Ehlmann, 2011). Gas seepage on Mars, as on Earth, can also be in the form of invisible diffuse exhalation from the ground (microseepage; see Etiope, 2015). Such visible or invisible seepages may develop in different geological settings on Mars, either sedimentary basins or basaltic, mafic, and ultramafic terrains, depending on the potential origin of $\mathrm{CH}_{4}$. After $\mathrm{CH}_{4}$ is formed, it may accumulate in porous and permeable rocks or clathrates acting as reservoirs. From these storage reservoirs, the gas may seep to the surface, preferentially along permeable pathways, such as faults and 
fractured rocks. For details on the main concepts of hypothetical $\mathrm{CH}_{4}$ production, storage, and seepage on Mars, see Oehler et al. (2005), Oehler and Allen (2010), Etiope et al. (2011a), Etiope et al. (2013), Etiope (2015), Oehler and Etiope (2017), and Etiope (2018).

How can we detect seepage on Mars? Based on analogy to the Tekirova ophiolites in Turkey where substantial amounts of $\mathrm{CH}_{4}$ are produced by active low-temperature $\left(<140^{\circ} \mathrm{C}\right)$ serpentinization and abiotic methanation, flux rates of several $\mathrm{mg} /\left(\mathrm{m}^{2} \cdot\right.$ day) could occur in martian rocks (Etiope et al., 2013). However, measurements of $\mathrm{CH}_{4}$ in the atmosphere taken $1 \mathrm{~m}$ above the ground, such as those performed by the Curiosity rover, may not be effective in revealing any seepage. As on Earth, the processes transporting $\mathrm{CH}_{4}$ to the surface and consuming $\mathrm{CH}_{4}$ en route may prevent its detection in the atmosphere even several centimeters above ground. These en route alterations can be important for Mars, where oxidative regolith $\mathrm{CH}_{4}$ chemistry could effectively remove methane. Opportune procedures and techniques must be adopted to detect seepage on Mars. One possibility could be to consider available surface gas geochemical techniques used on Earth, developed by petroleum geologists and geochemists, which allow the discovery of seepage and related underground hydrocarbon reservoirs all over the world using soil gas sampling, accumulation chambers, downhole analysis, and observations of surface mineralogical alterations (see Etiope, 2015; Oehler and Etiope, 2017, and references therein). In summary, geologic terrains characterized by regional faulting or including apparent mud volcanoes are the best places, according to present knowledge, to search for $\mathrm{CH}_{4}$ seepage on Mars, preferably above or near regions with olivine-bearing or sedimentary rocks. Extensive Earth-based experience in seepage sampling, detection, and analysis provides valuable guidance for future Mars exploration and technology development.

\section{ExoMars TGO}

The ExoMars program, a European Space AgencyRoscosmos cooperation with some NASA contributions, consists of two missions, one that was launched in 2016 and a second one that is scheduled for launch in 2020. The 2016 mission includes an orbiting satellite, the TGO, dedicated to the study of atmospheric trace gases to acquire information on possible ongoing geological or biological processes. This instrument is currently beginning normal science operations. Schiaparelli, an entry, descent, and landing demonstrator module, was intended to demonstrate the European Space Agency's technical prowess in safely landing modules on the surface of Mars, but failed at landing in November 2016. The 2020 mission is scheduled to deliver a $300 \mathrm{~kg}$ class rover and an instrumented landing platform to the martian surface using a landing system developed by the Russian Space Agency, Roscosmos.

The scientific objectives of the payload aboard the TGO and on the 2020 surface platform and rover are as follows: (1) to search for signs of past or present life on Mars; (2) to investigate how the water and geochemical environments vary, that is, by characterizing the distributions of relevant molecules in the atmosphere, on and near the surface, or as a function of depth in the shallow subsurface; (3) to investigate martian atmospheric trace gases and their sources; (4) to study the surface environment and identify hazards to future crewed missions to Mars; and (5) to investigate the planet's subsurface and deep interior to better understand the evolution and habitability of Mars. If successful, TGO will provide a major advance in the characterization of Mars' atmospheric chemistry.

In particular, the presence of two spectroscopic suites, Nadir and Occultation for Mars Discovery (NOMAD; Vandaele et al., 2015) and Atmospheric Chemistry Suite (ACS; Korablev et al., 2015), will help TGO cover several distinct areas:

(1) Analyzing the present-day chemical composition of the martian atmosphere through the detection of a broad suite of trace gases and key isotopes. Covering $14 \mathrm{UV}$, visible, and IR spectral ranges, NOMAD and ACS will ensure that a large number of species are detectable, such as $\mathrm{CO}_{2}$ (including ${ }^{13} \mathrm{CO}_{2},{ }^{17} \mathrm{OCO},{ }^{18} \mathrm{OCO}$, and $\mathrm{C}^{18} \mathrm{O}_{2}$ ), $\mathrm{CO}$ (including ${ }^{13} \mathrm{CO}$ and $\mathrm{C}^{18} \mathrm{O}$ ), $\mathrm{H}_{2} \mathrm{O}$ (including HDO), $\mathrm{NO}_{2}, \mathrm{~N}_{2} \mathrm{O}, \mathrm{O}_{3}, \mathrm{CH}_{4}$ (including ${ }^{13} \mathrm{CH}_{4}$ and $\left.\mathrm{CH}_{3} \mathrm{D}\right), \mathrm{C}_{2} \mathrm{H}_{2}, \mathrm{C}_{2} \mathrm{H}_{4}, \mathrm{C}_{2} \mathrm{H}_{6}, \mathrm{H}_{2} \mathrm{CO}, \mathrm{HCN}, \mathrm{OCS}, \mathrm{SO}_{2}$, $\mathrm{HCl}, \mathrm{HO}_{2}$, and $\mathrm{H}_{2} \mathrm{~S}$. The high resolution of the NOMAD IR channels will provide highly resolved spectra, allowing unambiguous separation of absorption lines and thus ensuring a high sensitivity for the search of trace gases (see Robert et al., 2016, for a detailed analysis of the sensitivity of the NOMAD instrument).

(2) Extending trace gas detection to the upper atmosphere to constrain atmospheric escape processes relating the present-day atmosphere to its past and future evolution. Simultaneous vertical profile measurements of $\mathrm{H}_{2} \mathrm{O}$, HDO, and atmospheric temperature will help investigate escape processes and evaluate upward fluxes and vertical diffusion up to the exobase.

(3) Understanding the chemistry to constrain the origin of $\mathrm{CH}_{4}$ (i.e., geophysical, exogenous, or biological) and destruction processes. NOMAD will contribute to solving the current question of the existence and persistence of martian $\mathrm{CH}_{4}$ by providing unequivocal measurements of its presence and variability, and it will clarify the processes related to its origin and destruction through the simultaneous detection of $\mathrm{CH}_{4}$ isotopologues and higher hydrocarbons such as $\mathrm{C}_{2} \mathrm{H}_{4}$ or $\mathrm{C}_{2} \mathrm{H}_{6}$.

(4) Studying gases related to possible ongoing geophysical and volcanic activity on Mars. Major gas releases associated with volcanic outgassing are expected to be sulfuric, that is, $\mathrm{SO}_{2}$ and $\mathrm{H}_{2} \mathrm{~S}$, which lie in the sensitivity range of NOMAD. This might help to distinguish whether $\mathrm{CH}_{4}$ is associated with either low-temperature (serpentinization, radiolysis of water, and subsequent Fischer-Tropsch-type reactions) or high-temperature magmatic processes.

The 2020 ExoMars rover will carry a comprehensive suite of instruments dedicated to geology and exobiology research. It will travel several kilometers searching for places potentially harboring signs of past or present life on Mars. Materials will be collected from the subsurface down to a depth of $2 \mathrm{~m}$ (in ideal situations) through the use of a dedicated drill and the powders examined in situ with the science payload. The descent platform will also carry payload instruments to study the martian surface environment.

The ExoMars rover will search for two types of life-related signatures, morphological and chemical, complemented by a detailed description of the geological context. Morphological 
biosignatures can be preserved on the surface of rocks, such as microbially mediated deposition of sediments, fossilized microbial mats, or stromatolitic mounds. Their study requires imaging systems capable of submillimeter resolution. Chemical biosignatures include chemical gradients, minerals, and isotopes preserved in the geologic record.

\section{Habitability and Biosignatures}

In the past few decades, the definition of habitability has changed dramatically as a result of the discovery of abundant life in the depths of Earth's oceans (around hydrothermal vents), the remarkable ability of extremophiles to tolerate conditions not imagined 50 years ago, and the discovery of abundant life in the terrestrial subsurface of our own planet. The old notion of "liquid water at the surface", has disappeared as the factor of importance, to be replaced by "a planet or moon that can supply the elements needed for life to emerge and thrive, be it on the surface, in the subsurface, or in a sub-ice-covered ocean." Thus, Mars is no longer necessarily beyond the habitable zone, and certainly the moons of the jovian and saturnian systems (e.g., Europa, Enceladus, Titan), located far from the "habitable" (a.k.a. Goldilocks) zone as defined in the past, are now reasonable candidates for habitable sites (Russell et al., 2014). We have moved from a habitable zone to a set of sites that meet the "habitable criteria" — a much different concept.

So, what are the criteria of habitability?

(1) Presence of a solvent in which electrochemical transformations can occur. An essential feature of life is the invention and use of enzymes to harvest and transform free energy from a geochemical environment where processes are otherwise slow or unworkable. Often thought of merely as "life's solvent," water is indispensable in that it acts as a shell to all proteins, and is necessary for their interaction with their substrates (Ball, 2008). Moreover, all known biochemical transformations (disequilibria conversions) are "biased" diffusional processes only known to operate in the extreme low Reynolds number regime offered by aqueous media (Astumian, 2006). This solvent would not have to be at the surface, but if life were global, the solvent would have to be widespread. Recent discovery of widespread excess ice in the subsurface (Boynton et al., 2002; Mitrofanov et al., 2002; Tokar et al., 2002; Bramson et al., 2015; Stuurman et al., 2016; Dundas et al., 2018) suggests that Mars is water rich.

(2) Presence of sources of free energy to support life. On Earth, we have abundant solar energy and abundant geochemical energy in the form of redox couples, both of which support terrestrial life. Chemical energy derived from photolysis of $\mathrm{CO}_{2}$ and $\mathrm{H}_{2} \mathrm{O}$ is available on Mars (Weiss et al., 2000). There is a potential for photo- and biochemical generation of organic molecules from $\mathrm{H}_{2} \mathrm{O}$ and $\mathrm{CO}_{2}$ on Mars, although no evidence has been forthcoming to date (Weiss et al., 2000). There are other energy sources (magnetic, heat, nuclear, and wind), but as far as we know, no earthly life (other than human) has solved the problem(s) of metabolizing any of these. Recent reports of microbes that live on electricity are an interesting addition to the redox style of life (Rowe et al., 2015), and could offer connections to life forms that utilize magnetism. The point is habitability will require available sources of free energy (i.e., appropriate disequilibria), and these should be assessed at any site where life is suspected to be present. Recent studies on the role of radiolysis not only in producing $\mathrm{H}_{2}$ but, via indirect oxidation of sulfide minerals, in producing sulfate as well, demonstrate novel mechanisms by which both essential electron donors $\left(\mathrm{CH}_{4}\right.$, $\mathrm{H}_{2}$ ) and electron acceptors (sulfate) can be provided to sustain subsurface chemolithotrophic communities, even in otherwise oligotrophic crystalline rocks billions of years in age (Lin et al., 2006; Li et al., 2016).

(3) Presence and availability of elements needed for life. Life as we know it is unique in its elemental composition-no known abundant mineral is composed of the same group of elements. With a few exceptions (such as Si-rich diatoms), life on Earth is composed of the same elements, in roughly the same ratios. While there is no need to argue that life elsewhere would be composed of the same elements, it is reasonable to suppose that life at another site will have its own composition that allows it to harvest energy, grow, reproduce, and evolve. Nevertheless, given that life exploits chemical and chemiosmotic energy, it would be hard to imagine it operating in the absence of $\mathrm{Fe}$ and $\mathrm{Ni}$ for hydrogenations and dehydrogenations, Mo/W for electron transfer, Co for methyl transfer, $\mathrm{P}$ for linking nucleotides and disequilibria transformations, and $\mathrm{S}$ for iron/sulfur clusters, and the cysteine/cystine redox cycle (Westheimer, 1987; Beinert, 2000; Nitschke and Russell, 2009; Nitschke et al., 2013).

Mars offers a unique combination of conditions for acquiring understanding not attainable by experiments elsewhere. To put this another way, there are no true Mars analog environments on Earth. Mars has only a few millibar of atmosphere, primarily composed of $\mathrm{CO}_{2}$ with very little oxygen or nitrogen. It has little or no surficial liquid water and very little organic carbon as well. Lacking a thick atmosphere, it thereby bathes in damaging ultraviolet and ionizing radiation. Thus, while Mars is roughly similar to Earth in size (half the Earth's diameter and hence about $10 \%$ its mass), chemical composition, and distance from the Sun-making it a candidate for comparison and interpretation-it is sufficiently different to provide tests not attainable on Earth. Irrespective of whether life is or was ever present on Mars, there are a number of key astrobiological issues that have been and will continue to be addressed through the study of our sister planet. Geological evidence and models suggest that early Mars was more Earth like, with a magnetic field, an ocean, warmer ambient temperatures than at present, a denser atmosphere, and perhaps even some rudimentary plate tectonics. Just how long the martian environment remained with such clement conditions, and whether life might have evolved during that time, is one of the key astrobiological questions that might be answered by detailed studies of Mars. In the following paragraphs, we focus on a few key components of habitability concerning methane on Mars. 


\subsection{Source identification}

The astrobiological relevance of $\mathrm{CH}_{4}$ on Mars pertains to the possible existence of life and/or habitability. If it can be established that $\mathrm{CH}_{4}$ is being injected into the martian atmosphere, and the rates can be deemed significant, then the planet is at least geochemically active and capable of $\mathrm{H}_{2}$ and eventually $\mathrm{CH}_{4}$-production. Given that both $\mathrm{H}_{2}$ and $\mathrm{CH}_{4}$ are common metabolites of life on Earth, the notion of extant life on Mars becomes a possibility. However, at the same time, production of $\mathrm{H}_{2}$ and $\mathrm{CH}_{4}$ can occur in water/rock reactions such as serpentinization and FTT reactions on Earth, although their kinetics as a function of temperature is still debated. While little is known about subsurface water flow, diffusion, and water/rock reactions on Mars (see recurring slope lineae observations possibly indicating the subsurface flow of water, Ojha et al., 2015), if such processes occur, then $\mathrm{H}_{2}$ and/or $\mathrm{CH}_{4}$ could possibly be generated abiotically (Lyons et al., 2005; Oze and Sharma, 2005; Onstott et al., 2006). Certainly, fracture waters down to at least $3 \mathrm{~km}$ depth in the Precambrian Shields of Earth (including Archean rocks of circa 3-2.7 Ga) contain large quantities of reduced gases (mM concentrations of $\mathrm{H}_{2}, \mathrm{CH}_{4}$, and higher hydrocarbons; see Sherwood Lollar et al., 2002, 2014).

A key to understanding the relationship of $\mathrm{CH}_{4}$ to the habitability of Mars (now or in the past) lies in the stable isotopic signature of any $\mathrm{CH}_{4}$ that is found (Allen et al., 2006). On Earth, the carbon isotope ratio $\left(e . g ., \delta^{13} \mathrm{C}\right)$ in biologically formed $\mathrm{CH}_{4}$ is highly enriched in ${ }^{12} \mathrm{C}$ relative to ${ }^{13} \mathrm{C}$ by methane-producing archaea, yielding $\delta^{13} \mathrm{C}$ values of $-60 \%$ or lighter (i.e., more negative). While strongly ${ }^{13} \mathrm{C}$ depleted methane would be an exciting finding because it would suggest a causal indication of present or past microbial life on Mars, interpretations must be tempered, since equally strong fractionations are associated with abiotic methanogenic processes. Hence, $\delta^{13} \mathrm{C}$ signatures and fractionation factors alone are insufficient to differentiate sources (Sherwood Lollar et al., 2006; McCollom et al., 2010; Etiope, 2018). Any isotopic analysis of $\mathrm{CH}_{4}$ must be coupled with multiple lines of evidence, including stable isotopic signatures of the potential carbon sources (e.g., $\mathrm{CO}_{2}$, $\mathrm{CO})$ or additional products of hydrocarbon synthesis (e.g., ethane, propane) and associated sulfur-bearing compounds or noble gases (Allen et al., 2006; Etiope and Sherwood Lollar, 2013). By contrast, unfractionated $\mathrm{CH}_{4}$ will be less definitive; depending on the reservoirs, formation pathways, enzymes involved, rates of production and consumption, and other variables, there should be plenty of ways to produce unfractionated $\mathrm{CH}_{4}$ biologically as well as abiotically. Correction of $\delta^{13} \mathrm{CH}_{4}$ values caused by atmospheric reactive losses must also be taken into account (Nair et al., 2005). In any case, it is clear that any well-documented large $\mathrm{CH}_{4}$ emissions would be a cause for excitement and further study.

\subsection{Climatic habitability}

In the past, at larger outgassing rates, reduced gases such as $\mathrm{H}_{2}$ and $\mathrm{CH}_{4}$ from the subsurface may have played a key role in the habitability on Mars. Atmospheres rich in $\mathrm{H}_{2}$ could supply the needed temperatures to sustain liquid water at the surface. Ramirez et al. (2014) demonstrate that an atmosphere containing 1.3-4 bar of $\mathrm{CO}_{2}$ and water, in addition to $5-20 \% \mathrm{H}_{2}$, could have raised the mean surface temperature of early Mars above the freezing point of water. The source could have been volcanic outgassing from a more reduced early martian mantle. Even low levels of methane supply to the surface could provide needed warming, if $\mathrm{CH}_{4}$ is emitted in a punctuated manner (to replenish atmospheric $\mathrm{CH}_{4}$ with a finite subsurface inventory). For example, Wordsworth et al. (2017) show that methane and hydrogen produced following aqueous alteration of Mars' crust could have combined with volcanically outgassed $\mathrm{CO}_{2}$ to form transient atmospheres and that methane could have acted as a powerful greenhouse gas on early Mars due to $\mathrm{CO}_{2}-\mathrm{CH}_{4}$ collision-induced absorption in the critical $250-500 \mathrm{~cm}^{-1}$ spectral window region. Kite et al. (2017) suggest that methane clathrates released by obliquity cycles may episodically build up to atmospheric levels sufficient for intermittent, lake-forming climates, assuming methane clathrate initially occupied more than $4 \%$ of the total volume in which it is thermodynamically stable.

The preceding discussion of outgassing evokes the question of whether or not plate tectonics is a requirement for habitability. Ancient Mars was tectonically active, but any such activity has long since stopped. This puts the study of life's history on Mars in a unique place in terms of addressing this question. If life did arise on early Mars, was it impossible for it to continue in the absence of geological cycling of the elements, as occurs on Earth? Recent evidence from the tectonically quiescent $2.7 \mathrm{Ga}$ cratons on Earth demonstrates that fracture propagation continues even in the absence of plate tectonics (Sleep and Zoback, 2007), and that hydrogen $\mathrm{H}_{2}$ (and $\mathrm{CH}_{4}$ ) production, as well as sulfate production, could continue on a geologic timescale even at low temperatures (Sherwood Lollar et al., 2014; Li et al., 2016). Such processes and timescales may provide relevant analogs for Mars, in addition to studies focused on high-temperature water-rock interactions on the relatively young $(<200 \mathrm{Ma})$ marine seafloor.

\section{Atmospheric Transport and Measurement Strategies}

Understanding the distribution and fate of $\mathrm{CH}_{4}$ in the martian atmosphere-as well as identifying potential surface sources-relies heavily on our understanding of atmospheric transport on Mars. Atmospheric observations from Mars orbiters over the last two decades have contributed to a fairly comprehensive picture of the structure of the martian atmosphere. The characterization of the middle atmosphere ( 50-100 km altitude) has been greatly improved through recent observations by both the Mars Climate Sounder on the Mars Reconnaissance Orbiter, covering altitudes between the surface and $\sim 80 \mathrm{~km}$ (Kleinböhl et al., 2009; McCleese et al., 2010), and Spectroscopy for Investigation of Characteristics of the Atmosphere of Mars on Mars Express, covering altitudes between 70 and $130 \mathrm{~km}$ (Forget et al., 2009). The upper atmosphere $(>100 \mathrm{~km})$ has been characterized during aerobraking with entry, descent, and landing density profile measurements (Withers and Smith, 2006). More recently, the Mars Atmosphere and Volatile Evolution (MAVEN) mission, with its focus on this atmospheric region, has been providing a wealth of new observations that will make significant contributions to our understanding of upper atmospheric dynamics and escape, indicating significant atmospheric mass loss in the last 4.5 Gyr (Jakosky et al., 2017). 
Numerical models are the primary means of representing our understanding of the martian atmosphere. Several stateof-the-art Mars general circulation models (MGCMs) for simulating atmospheric structure and dynamics are available in the community. These include the NASA Ames MGCM (Kahre et al., 2015), the Laboratoire de Météorologie Dynamique (LMD) MGCM (Forget et al., 1999; Navarro et al., 2014b), and the Mars Weather Research and Forecasting (MarsWRF) General Circulation Model (Richardson et al., 2007; Toigo et al., 2012, among others). Figure 5 shows a comparison of the atmospheric water cycle by the LMD GCM to Mars Year 26 observations by the Thermal Emission Spectrometer aboard the Mars Global Surveyor (from Navarro et al., 2014b). These results are consistent with more recent observational data (Tschimmel et al., 2008; Smith et al., 2009; Sindoni et al., 2011) and other MGCMs as well. Additional MGCMs available in the community include the Geophysical Fluid Dynamics Laboratory (GFDL) MGCM (Wilson and Hamilton, 1996; Greybush et al., 2012) and the Global Environmental Multiscale model (Daerden et al., 2015).

While comparisons of available measurements of atmospheric structure and aerosol distribution with MGCMs show agreement in many aspects, they also reveal significant discrepancies (McCleese et al., 2008; Forget et al., 2009; McDunn et al., 2010). Improvements in numerical models require the identification and quantification of the underlying dynamical and radiative processes that govern the martian atmosphere, as well as the chemical processes relevant to $\mathrm{CH}_{4}$ and other trace gases. Recent advances in our understanding of transport in the martian atmosphere include the recognition of the radiative influence of aerosols, and the significant impact large-scale dust storms have on atmospheric structure. However, water/ice clouds also exert a significant radiative influence on the atmosphere, mostly through absorption of infrared radiation emitted from the surface during the day. This radiative influence has a significant impact on atmospheric tides and increases the speed of the overturning meridional circulation (Madeleine et al., 2012; Kleinböhl et al., 2013; Steele et al., 2014), leading to an increase in the transport of aerosol and trace constituents toward the poles. Also, the coupling between the dust and water cycles leads to radiative dynamic feedbacks that have only recently been recognized (Kahre et al., 2015). Nevertheless, features such as detached dust layers in the middle atmosphere of Mars (Heavens et al., 2011; Heavens et al., 2015; see Fig. 6) and their variability (Heavens et al., 2014) lack a comprehensive explanation and indicate that significant shortcomings in our understanding of atmospheric transport still exist. The absorption of sunlight by dust layers can lead to local atmospheric warming, which affects the buoyancy of air parcels. Daerden et al. (2015) identified such a solar escalator effect by tracking dust layers in the northern polar region. Due to the higher insolation, it is expected that such effects are more vigorous at middle and low latitudes. Simulations with mesoscale models suggest that local dust heating can lift dust layers by $10-20 \mathrm{~km}$ in altitude within a few hours (Spiga et al., 2013; and Fig. 6). These processes are likely to play a major role in the vertical transport of aerosols and trace gases but are currently not well quantified or represented in MGCMs. Continued atmospheric observations targeted at understanding these processes and improvements in their representation in models are required to further our understanding of the dynamics of the martian atmosphere.

$\mathrm{CH}_{4}$ measurements on Mars have clearly demonstrated the critical need for enabling back-trajectory analyses. For instance, we cannot determine the source location of the TLSobserved $\mathrm{CH}_{4}$ plume because we do not have the ability to calculate back trajectories for Mars. Lefèvre and Forget (2009, with updates) presented preliminary studies in which their MGCM simulated ten putative source locations, all equally likely due to lack of observational constraints (see, e.g., Fig. 2b). In addition, atmospheric circulation can significantly affect atmospheric chemistry.

A prerequisite for carrying out accurate back-trajectory analyses is a detailed knowledge and representation of the atmospheric state. On Earth, such knowledge is gathered by assimilating atmospheric data from radiosondes and satellites into general circulation models. The results of these assimilations (called "reanalysis") are sufficiently accurate to be treated as the "true" atmospheric state. For accurate back-trajectory calculations, it is essential that this capability be developed for Mars, as free-running MGCMs do not represent the atmospheric state well enough to be applicable for studies at this level of detail. Initial efforts have
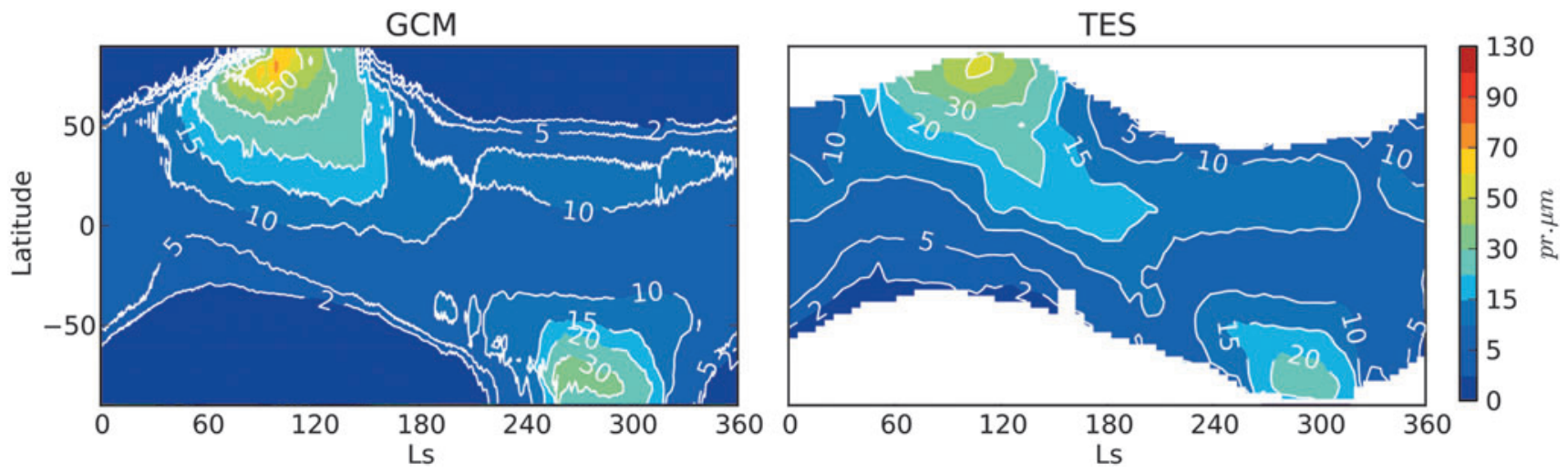

FIG. 5. (Left) Column-integrated, zonal mean daytime water abundance for present-day Mars, modeled by the LMD MGCM. (Right) Column-integrated, zonal mean daytime water abundance from the MGS-TES instrument for MY 26. From Navarro et al. (2014b). LMD, Laboratoire de Météorologie Dynamique; MGCM, Mars general circulation model; MGS, Mars Global Surveyor; TES, Thermal Emission Spectrometer. 

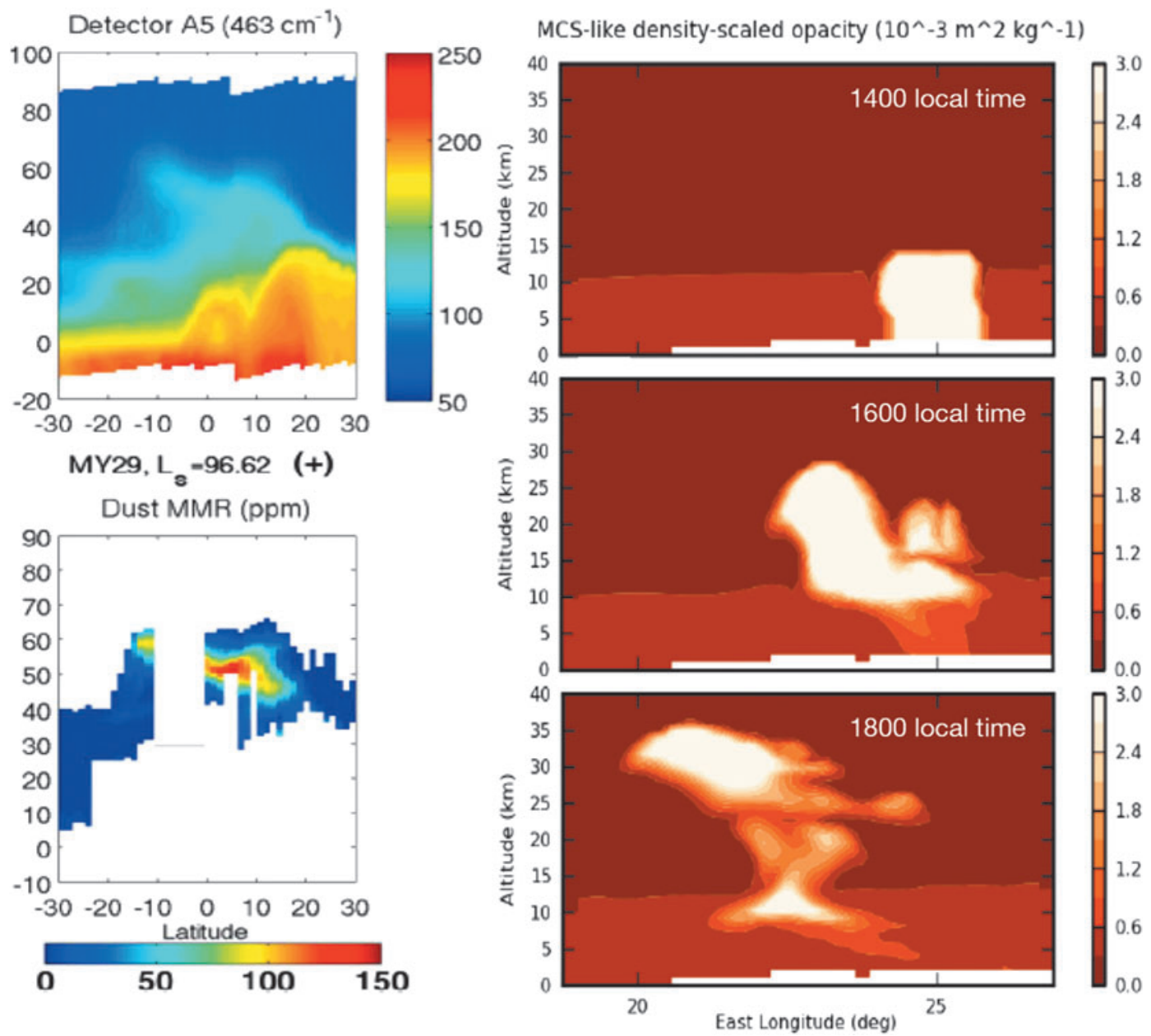

FIG. 6. (Left): Limb radiances at $463 \mathrm{~cm}^{-1}$ measured by MCS (top) and dust mass mixing ratio retrieved from MCS measurements (bottom), exhibiting a detached dust layer at 50-60 km altitude over Tharsis (Heavens et al., 2015). The density-scaled optical depth $\left(d_{z} \tau\right)$ is related to the optical depth at $0.67 \mu \mathrm{m}(\mathrm{d} \tau)$ by $d_{z} \tau=-d \tau / \rho$, where $\rho$ is atmospheric density in units of $\mathrm{kg} / \mathrm{m}^{3}$. (Right): Mesoscale model simulation showing density-scaled dust opacity in a so-called rocket dust storm, in which dust can be lifted to altitudes 30-40 km within a few hours (Spiga et al., 2013). MCS, Mars Climate Sounder.

been undertaken to assimilate temperature and/or aerosol distribution from spaceborne observations into MGCMs (Lee et al., 2011; Greybush et al., 2012; Navarro et al., 2014a; Steele et al., 2014). Assimilation models need to be run at sufficiently high spatial and temporal resolution to provide reanalyses of sufficient detail to be useful for backtrajectory calculations.

For this effort to be successful, suitable atmospheric observations must be available to be assimilated. This requires the continued operation of current assets, as well as the deployment of new assets. Assets deployed into Mars orbit need to measure atmospheric profiles of temperature or radiance, dust, water/ice, aerosol, and (ideally) water vapor. Measurements must have continuous global coverage on at least a daily basis to be useful for assimilation. Limb sounding in the thermal infrared can provide this kind of information with the required coverage from a low Mars orbit. Radio science measurements lack aerosol information and are unlikely to achieve the global coverage required to be suitable for assimilation. However, their highly accurate temperature measurements make them a good candidate for the validation of reanalyses. Another data set that might be suitable for assimilation is surface pressure obtained by a network of in situ sensors on the Mars surface, assuming that a sufficient number of nodes can be deployed with enough spatial coverage. This will require technological development.

If the short lifetime of $\mathrm{CH}_{4}$ on Mars suggested by previous measurements is confirmed by TGO, then a strong case can be made for an episodic release from sources. It will be important to capture episodic enhancements of $\mathrm{CH}_{4}$, as we have not yet discerned any predictable geographical or temporal pattern for such events. Therefore, $\mathrm{CH}_{4}$ measurements with global and quasicontinuous observational coverage are indispensable. TGO requires more than a month to attain quasiglobal coverage, which may not be sufficient.

One approach for achieving this goal is $\mathrm{CH}_{4}$ mapping from low Mars orbit with high spatial resolution. Measurement of reflected sunlight in the infrared in nadir/off-nadir geometry would be the preferred technique. The strongest $\mathrm{CH}_{4}$ lines are found at $\sim 3000 \mathrm{~cm}^{-1}$, which is also the band in which NOMAD targets its $\mathrm{CH}_{4}$ measurements (Robert et al., 2016). 
Absorption measurements of these lines with high spectral resolution $\left(\sim 0.1 \mathrm{~cm}^{-1}\right)$ provide column measurements of $\mathrm{CH}_{4}$. An imaging spectrometer would be the instrument of choice to obtain both high spatial coverage and resolution. This could be obtained with instruments developed for remote sensing of column $\mathrm{O}_{2}$ and $\mathrm{CO}_{2}$ in Earth's atmosphere in a wavelength range from 0.7 to $2 \mu \mathrm{m}$ (Crisp et al., 2012). This technology is basically available, but would have to be adapted for $\mathrm{CH}_{4}$ measurements on Mars. The small absorption signal from the expected $\mathrm{CH}_{4}$ levels at Mars will likely require a cooled spectrometer and detector array to keep pixel sizes small and integration times short such that high spatial resolution can be achieved. We note that NOMAD's cooler for nadir viewing measurements was descoped (Vandaele et al., 2015). The deployment of an instrument with a cooled spectrometer and detector array would hence provide a significant increase in sensitivity. The field-of-view of such an imaging spectrometer could be gimbaled in the cross-track direction to increase the swath width of the measurement and to allow targeted observations.

Interplanetary CubeSats and SmallSats may provide novel, low-cost means to deploy instrumentation for atmospheric and/or chemical studies from Mars orbit or on the martian surface. One approach is a CubeSat constellation in Mars orbit that could perform observations of atmospheric temperature, dust, and water/ice profiles. This could be achieved through thermal infrared limb sounding instrumentation. CubeSat technology would have to provide 3-axisstabilized attitude control and determination with sufficient accuracy for this kind of application; $<25$ arcsec 3 -axis has been demonstrated in Earth orbit using the Blue Canyon Technologies XACT hardware aboard the University of Colorado's Miniature X-ray Solar Spectrometer (MinXSS), which would need to be modified to operate without magnetic torquers for Mars (Mason et al., 2016). CubeSats positioned in Sun-synchronous orbits with nodes spread out in local time could provide global measurements at multiple local times, suitable for data assimilation and for studying atmospheric processes that occur on timescales less than half of one martian day (see, e.g., Fig. 6, right).

Another strategy is the deployment of a network of meteorological stations on the surface of Mars. The recently developed Mars ${ }_{\text {DROP }}$ concept enables the landing of small payloads on the surface of Mars (Staehle et al., 2015). A meteorological package consisting of in situ sensors for pressure, temperature, and humidity, as well as potentially a deployable wind mast, would have to be sufficiently miniaturized for a Mars ${ }_{\text {DROP }}$ shell. A network consisting of a sufficient number of stations could provide valuable measurements for constraining local near-surface weather, as well as global weather patterns, through data assimilation. This is critical for improving our understanding of circulation and trace gas transport, and thereby relating the observed concentrations to sources and sinks on Mars.

Direct wind measurements on Mars would be desirable to better characterize martian atmospheric dynamics and enable back-trajectory simulations. Martian wind measurements require technological innovations to become a feasible scientific target. TGO will not provide substantial improvements in wind measurements.

The need for atmospheric measurement networks on Mars has long been known and articulated (Planetary Science
Decadal Survey, 2011). Network sampling is necessary because martian atmospheric circulation closely interacts with the dust, $\mathrm{CO}_{2}$, and $\mathrm{H}_{2} \mathrm{O}$ cycles. Consequently, the transport, distribution, and fate of volatiles are complex and highly variable, requiring synoptic/network sampling to advance MGCM development. Although ExoMars TGO will map key trace volatiles and isotopologues with unprecedented sensitivity, it will not address the need for network measurements. Indeed, the Planetary Science Decadal Survey (2011) states the vision as follows:

\begin{abstract}
"Fundamental advances in our understanding of modern climate would come from a complete determination of the three-dimensional structure of the Martian atmosphere, from the surface boundary layer to the exosphere. This determination should be performed globally, ideally by combining measurements of wind, surface pressure, and temperature from landed and orbital payloads. Surface measurements are required in order to complement these measurements and to characterize the boundary layer and monitor accurately the long-term evolution of the atmospheric mass. On a global scale, a network of at least 16 meteorological stations would be ideal, and carrying a capable meteorological payload on all future landed missions to measure surface pressure, temperature, electrical fields, and winds would provide an excellent start to developing such a network. These investigations should be complemented by the systematic monitoring of the three-dimensional fields of water vapor, clouds, and surface frosts. Isotopic signatures of volatiles (such as heavy water, HDO) should also be monitored to investigate the signature of ancient reservoirs and to study fractionation processes (e.g., cloud microphysics). Finally, research and analysis should continue in order to improve the numerical climate modeling of the key atmospheric processes and to support laboratory research, notably in relation to the properties of carbon dioxide ice and its behavior under Martian conditions."
\end{abstract}

Cost realism has prevented substantial progress toward such an assimilated measurement program, although the advent of interplanetary SmallSats can change this landscape. We envision that multiple small instruments will fit into the ballast space of larger spacecraft, permitting future Mars missions to deploy multiple assets with minimal additional cost to the primary mission. In particular, photonic-integratedcircuit (PIC) technology can enable chip-sized sensors and complete interplanetary instruments in a cell phone form factor. Such technology can enable affordable deployment of multiple sensors capable of making simultaneous measurements from different locations and/or platforms (surface, airborne, orbital), as well as flexible/adaptive deployment approaches. For example, PIC heterodyne sensors can measure trace gases, isotope ratios, and wind speeds via solar occultation. Heterodyne spectrometers offer ultrahigh spectral resolution, without bulky dispersive elements or moving parts, and shot-noise-limited signal-to-noise ratio. PIC technology enables heterodyne spectrometers-on-a-chip residing in the focal plane of a minitelescope to detect sunlight that has propagated through the planetary atmosphere. Amplitudes of absorption lines observed in the sunlight indicate molecular abundances, while ratios between different rotational/vibrational lines indicate atmospheric temperatures (Mahieux et al., 2010; Vandaele et al., 2015). In addition, Doppler shifts in line-center wavelengths indicate wind speeds (Sonnabend et al., 2006). These nanospectrometers 
could conduct limb observations from orbital and airborne platforms, as well as upward-looking observations from CubeSat-sized landers.

\section{Conclusions}

The $\mathrm{CH}_{4}$ measurements by MSL-TLS raise two fundamental challenges. First, the observed seasonal variability of $\mathrm{CH}_{4}$ is incompatible with the standard models for the physics and chemistry of the martian atmosphere. Second, the observed bursts of $\mathrm{CH}_{4}$ demand thus far unknown sources and/or modulation mechanisms on Mars. We take a broader view of the possible origins of $\mathrm{CH}_{4}$ on Mars to include more general questions related to the present and past habitability of Mars and the origin of life on Mars. Existing hypotheses for martian $\mathrm{CH}_{4}$ sources include gas-water-rock chemistry and microbes (either extinct or extant methanogens). If proven, the former implies the existence of environments offering liquid water and chemical sources of energy - that is, habitability - while the latter implies the discovery of life on Mars.

Resolving the $\mathrm{CH}_{4}$ sources and sinks on Mars will require model development and technology development strategies. Solving these planetary-scale puzzles requires a concerted research effort across many disciplines. The following is a summary listing the main recommendations of this article:

(1) Advancing our understanding of the potential for life and habitability on Mars requires an interdisciplinary study of atmospheric chemistry and dynamics, subsurface biogeochemistry, astrobiology, planetary geology, and geophysics (Section 1).

(2) The martian atmosphere and surface are an overwhelmingly oxidizing environment that is inhospitable to life, since life requires redox gradients as an essential source of energy. There should be a concerted effort to search for subsurface redox gradients that could serve as energy sources for life on Mars (Sections 4 and 5).

(3) To discriminate between abiotic and biological sources of $\mathrm{CH}_{4}$ on Mars, future work should include studies of $\mathrm{CH}_{4}$ isotopes, alkane abundance ratios, $\mathrm{H}_{2}$ concentration, and species such as acetic acid. More insight is needed on serpentinization and FTT reactions, specifically under which conditions they effectively operate (temperature, pressure, catalysts) and how widespread such processes occur on ancient and modern-day Mars (Section 4).

(4) Seepage should exist on Mars, and it may provide natural access for characterizing the martian subsurface. Specific surface manifestations in association with faults and fractured rocks, analogous to those observed on Earth, can indicate seepage on Mars. Geological terrains characterized by regional faulting or containing apparent mud volcanoes, preferably above or near regions with evidence for alteration of mafic or ultramafic igneous rocks or sedimentary rocks by hydration, are the most promising places to search for seepage on Mars (Section 5).

(5) A hitherto unknown process is responsible for the short lifetime of $\mathrm{CH}_{4}$ on Mars. Powerful oxidants, such as $\mathrm{O}, \mathrm{O}_{3}, \mathrm{H}_{2} \mathrm{O}_{2}$, nitrate, and perchlorate, exist in the atmosphere or on the surface, and they can possibly shorten the lifetime of methane. However, any plausible new candidate processes that destroy $\mathrm{CH}_{4}$ must not significantly change the well-determined lifetimes of atmospheric species such as $\mathrm{CO}$ and $\mathrm{H}_{2}$ (Section 3).

(6) $\mathrm{TLS} \mathrm{CH}_{4}$ measurements on Mars have demonstrated a need for back-trajectory analyses to track down methane sources. A realistic MGCM requires assimilation of global observations (Section 8).

(7) Global observations require the deployment of new assets to measure atmospheric profiles of wind, surface pressure, temperature, dust, water/ice, and water vapor. Measurements need to have continuous global coverage to be useful for assimilation, motivating technological innovation (Section 8).

(8) New technologies suited for CubeSat/SmallSat-inspired platforms are key to enabling feasible measurement networks on Mars to perform observations of atmospheric composition, wind, surface pressure, temperature, dust, and water/ice profiles. Ideally, the network should comprise multiple vantage points (e.g., orbital and land based) to provide global, 4D (spatial and temporal) characterization (Section 8).

In addition, chemical characterization of the martian subsurface (down to the theoretical groundwater stability depth, which can be as deep as a few $\mathrm{km}$ ) is pivotal to better constrain the sources of methane. Ideally, we need (a) higher resolution and deeper subsurface sounding (e.g., radar and preferably low-frequency electromagnetic sounding) to obtain a more global and refined understanding of the subsurface volatile, liquid water, brine, ice, and clathrate inventory and (b) drilling operations to characterize the chemical composition and redox state of the subsurface (Sections 4 and 8).

As we conclude the writing of this article, we anticipate initial announcements of $\mathrm{CH}_{4}$ measurement results from the ExoMars mission. This will be a major signpost in the pursuit of understanding methane on Mars, no matter the outcome. If ExoMars observes significant levels of methane on Mars, the global mapping with unprecedented sensitivity will guide future exploration strategies. On the contrary, a nondetection by ExoMars will not rule out localized hotspots obscured by atmospheric mixing/dilution in the large spatial resolution volume of the instruments or vertical trapping (by the atmospheric boundary layer, preventing methane from reaching observable altitudes) (Fonseca et al., 2018). Thus, either of these scenarios will, in fact, elevate the need to better understand the dynamics of methane transport/mixing on Mars and the need to implement the measurement and modeling capabilities discussed in Section 8 .

Eigenbrode et al. (2018) and Orosei et al. (2018) recently reperted discoveries of complex organic compounds and ground water on Mars. These discoveries might have implications for the origin of $\mathrm{CH}_{4}$, although we have not had the chance to study these implications in earnest.

\section{Acknowledgments}

We dedicate this article to JPL scientist Mark Allen, whose spirit of generosity inspired many of the conversations and much of the work that brought us together. This work was initiated and supported by the W.M. Keck Institute for Space Studies. We thank the Director of the Keck Institute for Space Studies, Tom Prince, the Executive Director, Michele Judd, and the capable and dedicated KISS staff for hosting and supporting the workshops that led to this article. We thank 
Charles Carter for the cover illustration and Meg Rosenberg for her work on editing and formatting. We thank Danica Adams, Siteng Fan, Amanda Gao, Mimi Gerstell, Yancheng Luo, Aimee Oz, Andrew Sappey, Sindhoora Tallapragada, and Kyle Weng for their efforts in editing the article. We thank Daniel Stolper for his participation and input in the workshop. The research was partly carried out at the Jet Propulsion Laboratory, California Institute of Technology, under a contract with the National Aeronautics and Space Administration.

\section{Author Disclosure Statement}

No competing financial interests exist.

\section{References}

Abrajano, T.A., Sturchio, N.C., Kennedy, B.M., Lyon, G.L., Muehlenbachs, K., and Bohlke, J.K. (1990) Geochemistry of reduced gas related to serpentinization of the Zambales ophiolite, Philippines. Appl Geochem 5:625-630.

Allen, M., Sherwood Lollar, B., Runnegar, B., Oehler, D.Z., Lyons, J.R., Manning, C.E., and Summers, M.E. (2006) Is Mars alive? Eos 87:433-439.

Anbar, A.D., Leu, M.T., Nair, H.A., and Yung, Y.L. (1993) Adsorption of HOx on aerosol surfaces: implications for the atmosphere of Mars. J Geophys Res 98:10933-10940.

Astumian, R.D. (2006) The unreasonable effectiveness of equilibrium theory for interpreting nonequilibrium experiments. Am J Phys 74:683-688.

Atreya, S.K., Mahaffy, P.R., and Wong, A.-S. (2007) Methane and related trace species on Mars: origin, loss, implications for life, and habitability. Planet Space Sci 55:358-369.

Atreya, S.K., Wong, A.-S., Renno, N.O., Farrell, W.M., Delory, G.T., Sentman, D.D., Cummer, S.A., Marshall, J.R., Rafkin, S.C.R., and Catling, D.C. (2006) Oxidant enhancement in Martian dust devils and storms: implications for life and habitability. Astrobiology 6:439-450.

Ball, P. (2008) Water as an active constituent in cell biology. Chem Rev 108:74-108.

Batalha, N.E., Kopparapu, R.K., Haqq-Misra, J., and Kasting, J.F. (2016) Climate cycling on early Mars caused by the carbonate-silicate cycle. Earth Planet Sci Lett 455:7-13.

Beinert, H. (2000) A tribute to sulfur. Eur J Biochem 267:5657-5664.

Boynton, W.V., Feldman, W.C., Squyres, S.W., Prettyman, T.H., Brückner, J., Evans, L.G., Reedy, R.C., Starr, R., Arnold, J.R., Drake, D.M., Englert, P.A.J., Metzger, A.E., Mitrofanov, I., Trombka, J.I., D'Uston, C., Wänke, H., Gasnault, O., Hamara, D.K., Janes, D.M., Marcialis, R.L., Maurice, S., Mikheeva, I., Taylor, G.J., Tokar, R., and Shinohara, C. (2002) Distribution of hydrogen in the near surface of Mars: evidence for subsurface Ice deposits. Science 297:81-85.

Bramson, A.M., Byrne, S., Putzig, N.E., Sutton, S., Plaut, J.J., Brothers, C., and Holt, J.W. (2015) Widespread excess ice in Arcadia Planitia, Mars. Geophys Res Lett 42:6566-6574.

Branscomb, E., Biancalani, T., Goldenfeld, N., and Russell, M. (2017) Escapement mechanisms and the conversion of disequilibria; the engines of creation. Phys Rep 677:1-60.

Bristow, T.F., Bish, D.L., Vaniman, D.T., Morris, R.V., Blake, D.F., Grotzinger, J.P., Rampe, E.B., Crisp, J.A., Achilles, C.N., Ming, D.W., Ehlmann, B.L., King, P.L., Bridges, J.C., Eigenbrode, J.L., Sumner, D.Y., Chipera, S.J., Moorokian, J.M., Treiman, A.H., Morrison, S.M., Downs, R.T., Farmer, J.D., Marais, D.D., Sarrazin, P., Floyd, M.M., Mischna, M.A., and McAdam, A.C. (2015) The origin and implications of clay minerals from Yellowknife Bay, Gale crater, Mars. American Mineralogist 100:824-836.

Cairns-Smith, A.G. and Hartman, H. (1986) Clay Minerals and the Origin of Life. Cambridge University Press, Cambridge.

Chastain, B.K. and Chevrier, V. (2007), Methane clathrate hydrates as a potential source for Martian atmospheric methane. Planet Space Sci 55:1246-1256.

Crisp, D., Fisher, B.M., O’Dell, C., Frankenberg, C., Basilio, R., Bosch, H., Brown, L.R., Castano, R., Connor, B., Deutscher, N.M., Eldering, A., Griffith, D., Gunson, M., Kuze, A., Mandrake, L., McDuffie, J., Messerschmidt, J., Miller, C.E., Morino, I., Natraj, V., Notholt, J., O’Brien, D.M., Oyafuso, F., Polonsky, I., Robinson, J., Salawitch, R., Sherlock, V., Smyth, M., Suto, H., Taylor, T.E., Thompson, D.R., Wennberg, P.O., Wunch, D., and Yung, Y.L. (2012) The ACOS $\mathrm{CO} 2$ retrieval algorithm-part II: global $\mathrm{X}_{\mathrm{CO} 2}$ data characterization. Atmos Meas Tech 5:687-707.

Daerden, F., Whiteway, J.A., Neary, L., Komguem, L., Lemmon, M.T., Heavens, N.G., Cantor, B.A., Hébrard, E., and Smith, M.D. (2015) A solar escalator on Mars: self-lifting of dust layers by radiative heating. Geophys Res Lett 42:7319-7326.

Dundas, C.M., Bramson, A.M., Ojha, L., Wray, J.J., Mellon, M.T., Byrne, S., McEwen, A.S., Putzig, N.E., Viola, D., Sutton, S., Clark, E., and Holt, J.W. (2018) Exposed subsurface ice sheets in the Martian mid-latitudes. Science 359:199-201.

Ehlmann, B.L., Anderson, F.S., Andrews-Hanna, J., Catling, D.C., Christensen, P.R., Cohen, B.A., Dressing, C.D., Edwards, C.S., Elkins-Tanton, L.T., Farley, K.A., Fassett, C.I., Fischer, W.W., Fraeman, A.A., Golombek, M.P., Hamilton, V.E., Hayes, A.G., Herd, C.D.K., Horgan, B., Hu, R., Jakosky, B.M., Johnson, J.R., Kasting, J.F., Kerber, L., Kinch, K.M., Kite, E.S., Knutson, H.A., Lunine, J.I., Mahaffy, P.R., Mangold, N., McCubbin, F.M., Mustard, J.F., Niles, P.B., Quantin-Nataf, C., Rice, M.S., Stack, K.M., Stevenson, D.J., Stewart, S.T., Toplis, M.J., Usui, T., Weiss, B.P., Werner, S.C., Wordsworth, R.D., Wray, J.J., Yingst, R.A., Yung, Y.L., and Zahnle, K.J. (2016) The sustainability of habitability on terrestrial planets: insights, questions, and needed measurements from Mars for understanding the evolution of Earth-like worlds. J Geophys Res 121:1927-1961.

Ehlmann, B.L., Mustard, J.F., Murchie, S.L., Bibring, J.P., Meunier, A., Fraeman, A.A., and Langevin, Y. (2011) Subsurface water and clay mineral formation during the early history of Mars. Nature 479:53-60.

Eigenbrode, J.L., Summons, R.E., Steele, A., Freissinet, C., Millan, M., Navarro-González, R., Sutter, B., McAdam, A.C., Franz, H.B., Glavin, D.P., Archer, P.D., Mahaffy, P.R., Conrad, P.G., Hurowitz, J.A., Grotzinger, J.P., Gupta, S., Ming, D.W., Sumner, D.Y., Szopa, C., Malespin, C., Buch, A., and Coll, P. (2018) Organic matter preserved in 3-billionyear-old mudstones at Gale crater, Mars. Science 360:1096.

Ellis, R.J. (2001) Macromolecular crowding: obvious but underappreciated. Trends Biochem Sci 26:597-604.

Etiope, G. (2015) Natural Gas Seepage, The Earth's Hydrocarbon Degassing. Springer International Publishing, Switzerland.

Etiope, G. (2018) Understanding the origin of methane on Mars through isotopic and molecular data from the ExoMars orbiter. Planet Space Sci 159:93-96.

Etiope, G., Ehlmann, B.L., and Schoell, M. (2013) Low temperature production and exhalation of methane from serpentinized rocks on Earth: a potential analog for methane production on Mars. Icarus 224:276-285.

Etiope G. and Ionescu, A. (2015) Low-temperature catalytic $\mathrm{CO}_{2}$ hydrogenation with geological quantities of ruthenium: a 
possible abiotic $\mathrm{CH}_{4}$ source in chromitite-rich serpentinized rocks. Geofluids 15:438-452.

Etiope, G., Oehler, D.Z., and Allen, C.C. (2011a) Methane emissions from Earth's degassing: implications for Mars. Planet Space Sci 59:182-185.

Etiope, G., Schoell, M., and Hosgormez, H. (2011b) Abiotic methane flux from the Chimaera seep and Tekirova ophiolites (Turkey): understanding gas exhalation from low temperature serpentinization and implications for Mars. Earth Planet Sci Lett 310:96-104.

Etiope, G. and Sherwood Lollar, B. (2013) Abiotic methane on Earth. Rev Geophys 51:276.

Fonseca, R.M., Zorzano-Mier, M-P, and Martín-Torres, J. (2018) Planetary boundary layer and circulation dynamics at Gale Crater. Mars. Icarus 302:537-559.

Fonti, S. and Marzo, G.A. (2010) Mapping the methane on Mars. Astron Astrophys 512:A51.

Forget, F., Hourdin, F., Fournier, R., Hourdin, C., Talagrand, O., Collins, M., Lewis, S.R., Read, P.L., Huot, J.-P. (1999), Improved general circulation models of the Martian atmosphere from the surface to above $80 \mathrm{~km}$. J Geophys Res 104: 24155-24175.

Forget, F., Montmessin, F., Bertaux, J.-L., González-Galindo, F., Lebonnois, S., Quémerais, E., Reberac, A., Dimarellis, E., and López-Valverde, M.A. (2009) Density and temperatures of the upper Martian atmosphere measured by stellar occultations with Mars Express SPICAM. J Geophys Res 114:E01004.

Formisano, V., Atreya, S., Encrenaz, T., Ignatiev, N., and Giuranna, M. (2004) Detection of methane in the atmosphere of Mars. Science 306:1758-1761.

Fries, M., Christou, A., Archer, D., Conrad, P., Cooke, W., Eigenbrode, J., Kate, I.L.T., Matney, M., Niles, P., Sykes, M., Steele, A., and Treiman, A. (2016) A cometary origin for Martian atmospheric methane. Geochem Perspect Lett 2:10-23.

Fuchs, G. (1989) Alternative pathways of autotrophic carbon dioxide fixation in autotrophic bacteria. In Biology of Autotrophic Bacteria, edited by H.G. Schlegel, Science Technical, Madison, WI.

Gaillard, F. and Scaillet B. (2014) A theoretical framework for volcanic degassing chemistry in a comparative planetology perspective and implications for planetary atmospheres. Earth Planet Sci Lett 403:307-316.

Geminale, A., Formisano, V., and Sindoni, G. (2011) Mapping methane in Mars atmosphere with PFS-MEX data. Planet Space Sci 59:137-148.

Gough, R.V., Turley, J.J., Ferrell, G.R., Cordova, K.E., Wood, S.E., DeHaan, D.O.D., Mckay, C.P., Toon, O.B., and Tolbert, M.A. (2011) Can rapid loss and high variability of Martian methane be explained by surface $\mathrm{H}_{2} \mathrm{O}_{2}$ ? Planet Space Sci 59: 238-246.

Greybush, S.J., Wilson, R.J., Hoffman, R.N., Hoffman, M.J., Miyoshi, T., Ide, K., McConnochie, T., and Kalnay, E. (2012) Ensemble Kalman filter data assimilation of Thermal Emission Spectrometer (TES) profiles into a Mars GCM. J Geophys Res 117:E11008.

Grimm, R.E., Harrison, K.P., Stillman, D.E., and Kirchoff, M.R. (2017) On the secular retention of ground water and ice on Mars. J Geophys Res 122:94-109.

Grotzinger, J.P., Gupta, S., Malin, M.C., Rubin, D.M., Schieber, J., Siebach, K., Sumner, D.Y., Stack, K.M., Vasavada, A.R., Arvidson, R.E., Calef, F., Edgar, L., Fischer, W.F., Grant, J.A., Griffes, J., Kah, L.C., Lamb, M.P., Lewis, K.W., Mangold, N., Minitti, M.E., Palucis, M., Rice, M., Williams,
R.M.E., Yingst, R.A., Blake, D., Blaney, D., Conrad, P., Crisp, J., Dietrich, W.E., Dromart, G., Edgett, K.S., Ewing, R.C., Gellert, R., Hurowitz, J.A., Kocurek, G., Mahaffy, P., McBride, M.J., McLennan, S.M., Mischna, M., Ming, D., Milliken, R., Newsom, H., Oehler, D., Parker, T.J., Vaniman, D., Wiens, R.C., and Wilson, S.A. (2015) Deposition, exhumation, and paleoclimate of an ancient lake deposit, Gale crater, Mars. Science 350:aac7575.

Grotzinger, J.P., Sumner, D.Y., Kah, L.C., Stack, K., Gupta, S., Edgar, L., Rubin, D., Lewis, K., Schieber, J., Mangold, N., Milliken, R., Conrad, P.G., DesMarais, D., Farmer, J., Siebach, K., Calef, F. 3rd, Hurowitz, J., McLennan, S.M., Ming, D., Vaniman, D., Crisp, J., Vasavada, A., Edgett, K.S., Malin, M., Blake, D., Gellert, R., Mahaffy, P., Wiens, R.C., Maurice, S., Grant, J.A., Wilson, S., Anderson, R.C., Beegle, L., Arvidson, R., Hallet, B., Sletten, R.S., Rice, M., Bell, J., 3rd, Griffes, J., Ehlmann, B., Anderson, R.B., Bristow, T.F., Dietrich, W.E., Dromart, G., Eigenbrode, J., Fraeman, A., Hardgrove, C., Herkenhoff, K., Jandura, L., Kocurek, G., Lee, S., Leshin, L.A., Leveille, R., Limonadi, D., Maki, J., McCloskey, S., Meyer, M., Minitti, M., Newsom, H., Oehler, D., Okon, A., Palucis, M., Parker, T., Rowland, S., Schmidt, M., Squyres, S., Steele, A., Stolper, E., Summons, R., Treiman, A., Williams, R., Yingst, A., and MSL Science Team. (2014) A habitable fluvio-lacustrine environment at Yellowknife Bay, Gale crater, Mars. Science 343:1242777.

Harold, F.M. (2001) Gleanings of a chemiosmotic eye. BioEssays 23:848-855.

Hartman, H. (1998) Photosynthesis and the origin of life. Origins Life Evol Biosphere 28:515-521.

Hazen, R.M., Papineau, D., Bleeker, W., Downs, R.T., Ferry, J.M., McCoy, T.J., Sverjensky, D.A., and Yang, H. (2008) Mineral evolution. Am Mineral 93:1693-1720.

Heavens, N.G., Richardson, M.I., Kleinböhl, A., Kass, D.M., McCleese, D.J., Abdou, W., Benson, J.L., Schofield, J.T., Shirley, J.H., and Wolkenberg, P.M. (2011) Vertical distribution of dust in the Martian atmosphere during northern spring and summer: high-altitude tropical dust maximum at northern summer solstice. J Geophys Res 116:E01007.

Heavens, N.G., Johnson, M.S., Abdou, W.A., Kass, D.M., Kleinböhl, A., McCleese, D.J., Shirley, J.H., and Wilson, R.J. (2014) Seasonal and diurnal variability of detached dust layers in the tropical Martian atmosphere. J Geophys Res 119: 1748-1774.

Heavens, N.G., Cantor, B.A., Hayne, P.O., Kass, D.M., Kleinböhl, A., McCleese, D.J., Piqueux, S., Schofield, J.T., and Shirley, J.H. (2015) Extreme detached dust layers near Martian volcanoes: evidence for dust transport by mesoscale circulations forced by high topography. Geophys Res Lett 42:3730-3738.

Holm, N.G., Oze, C., Mousis, O., Waite, J.H., and GuilbertLepoutre, A. (2015) Serpentinization and the formation of $\mathrm{H}_{2}$ and $\mathrm{CH}_{4}$ on celestial bodies (planets, moons, comets). Astrobiology 15:587-600.

Hu, R., Seager, S., and Bains, W. (2012) Photochemistry in terrestrial exoplanet atmospheres, I. Photochemistry model and benchmark cases. Astrophys J 76, 166-194.

Hu, R., Kass, D.M., Ehlmann, B.L., and Yung, Y.L. (2015) Tracing the fate of carbon and the atmospheric evolution of Mars. Nature Commum 6:10003.

Hu, R., Bloom, A.A., Gao, P., Miller, C.E., and Yung, Y.L. (2016) Hypotheses for near-surface exchange of methane on Mars. Astrobiology 16:539-550.

Jakosky, B.M., Slipski, M., Benna, M., Mahaffy, P., Elrod, M., Yelle, R., Stone, S., and Alsaeed, N. (2017) Mars' 
atmospheric history derived from upper-atmosphere measurements of ${ }^{38} \mathrm{Ar} /{ }^{36} \mathrm{Ar}$. Science 355:1408-1410.

Jensen, S.J.K., Skibsted, J., Jakobsen, H.J., Kate, I.L.T., Gunnlaugsson, H.P., Merrison, J.P., Finster, K., Bak, E., Iversen, J.J., Kondrup, J.C., and Nørnberg, P. (2014) A sink for methane on Mars? The answer is blowing in the wind. Icarus 236:24-27.

Kahre, M.A., Hollingsworth, J.L., Haberle, R.M., and Wilson, R.J. (2015) Coupling the Mars dust and water cycles: the importance of radiative-dynamic feedbacks during northern hemisphere summer. Icarus 260:477-480.

Keppler, F., Vigano, I., McLeod, A., Ott, U., Früchtl, M., and Röckmann, T. (2012) Ultraviolet-radiation-induced methane emissions from meteorites and the Martian atmosphere. Nature 486:93-96.

Kerr, R.A. (2012) Could a whiff of methane revive the exploration of Mars? Science 336:1500-1503.

Kite, E.S., Goldblatt, C., Gao, P., Mischna, M.A., Mayer, D.P., and Yung, Y.L. (2017) Methane bursts as a trigger for intermittent lake-forming climates on post-Noachian Mars. Nat Geosci 10:737-744.

Kleinböhl, A., Schofield, J.T., Kass, D.M., Abdou, W.A., Backus, C.R., Sen, B., Shirley, J.H., Lawson, W.G., Richardson, M.I., Taylor, F.W., Teanby, N.A., and McCleese, D.J. (2009) Mars climate sounder limb profile retrieval of atmospheric temperature, pressure, dust and water ice opacity. J Geophys Res 114:E10006.

Kleinböhl, A., Wilson, R. J., Kass, D.M., Schofield, J.T., and McCleese, D.J. (2013) The semi-diurnal tide in the middle atmosphere of Mars. Geophys Res Lett 40:1952-1959.

Korablev, O., Montmessin, F., Fedorova, A.A., Ignatiev, N., Shakun, A., Trokhimovskiy, A.V., Grigoriev, A.V., Anufreichik, K.A., and Kozlova, T.O. (2015) ACS experiment for atmospheric studies on "ExoMars-2016" orbiter. Sol Syst Res 49:529-537.

Krasnopolsky, V., Maillard, J.P., and Owen, T.C. (2004) Detection of methane in the Martian atmosphere: evidence for life? Icarus 172:537-547.

Kress, M.E. and McKay, C.P. (2004) Formation of methane in comet impacts: implications for Earth, Mars, and Titan. Icarus 168:475-483.

Lammer H., Chassefiere, E., and Karatekin, O. (2013) Outgassing history and escape of the Martian atmosphere and water inventory. Space Sci Rev 174:113-154.

Lane, N. (2017) Proton gradients at the origin of life. BioEssays 39. DOI: 10.1002/bies.201600217.

Lee, C, Lawson, WG, Richardson, MI, Anderson, JL, Collins, N, Hoar, T., and Mischna, M (2011) Demonstration of ensemble data assimilation for Mars using DART, MarsWRF, and radiance observations from MGS TES. $J$ Geophys Res 116. DOI: 10.1029/2011JE003815.

Lefèvre, F. and Forget, F. (2009) Observed variations of methane on Mars unexplained by known atmospheric chemistry and physics. Nature 460:720-723.

Li, L, Wing, B.A., Bui, T.H., McDermott, J.M., Slater, G.F., Wei, S., Lacrampe-Couloume, G., and Sherwood Lollar, B. (2016) Sulfur mass-independent fractionation in subsurface fracture waters indicates a long-standing sulfur cycle in Precambrian rocks. Nat Commun 7:13252.

Lin, L.-H., Wang, P.-L., Rumble, D., Lippmann-Pipke, J., Boice, E., Pratt, L., Sherwood Lollar, B., Brodie, E., Hazen, T., Andersen, G., DeSantis, T., Moser, D.P., Kershaw, D., and Onstott, T.C. (2006) Long-term sustainability of a highenergy, low-diversity crustal biotome. Science 314:479-482.
Lubner, C.E., Jennings, D.P., Mulder, D.W., Schut, G.J., Zadvornyy, O.A., Hoben, J.P., Tokmina-Lukaszewska, M., Berry, L., Nguyen, D.M., Lipscomb, G.L., Bothner, B., Jones, A.K., Miller, A.F., King, P.W., Adams, M.W.W., and Peters, J.W. (2017) Mechanistic insights into energy conservation by flavin-based electron bifurcation. Nat Chem Biol 13:655-659.

Luo, Y.H., Chen, R., Wen, L.L., Meng, F., Zhang, Y., Lai, C.Y., Rittmann, B.E., Zhao, H.P., and Zhang, P. (2015) Complete perchlorate reduction using methane as the sole electron donor and carbon source. Environ Sci Technol 49: 2341-2349.

Lyons, J.R., Manning, C., and Nimmo, F. (2005) Formation of methane on Mars by fluid-rock interaction in the crust. Geophys Res Lett 32:L13201.

Madeleine, J.-B., Forget, F., Millour, E., Navarro, T., and Spiga, A. (2012) The influence of radiatively active water ice clouds on the Martian climate. Geophys Res Lett 39:L23202.

Maden, B.E.H. (2000) Tetrahydrofolate and tetrahydromethanopterin compared: functionally distinct carriers in C-1 metabolism. Biochem J 350:609-629.

Mahaffy, P.R., Webster, C.R., Stern, J.C., Brunner, A.E., Atreya, S.K., Conrad, P.G., Domagal-Goldman, S., Eigenbrode, J.L., Flesch, G.J., Christensen, L.E., Franz, H.B., Freissinet, C., Glavin, D.P., Grotzinger, J.P., Jones, J.H., Leshin, L.A., Malespin, C., McAdam, A.C., Ming, D.W., Navarro-Gonzalez, R., Niles, P.B., Owen, T., Pavlov, A.A., Steele, A., Trainer, M.G., Williford, K.H., Wray, J.J., and the MSL Science Team. (2015) The imprint of atmospheric evolution in the D/H of Hesperian clay minerals on Mars. Science 347:412-414.

Mahieux, A., Vandaele, A.C., Neefs, E., Robert, S., Wilquet, V., Drummond, R., Fedorova, A.A., and Bertaux, J.L. (2010) Densities and temperatures in the Venus mesosphere and lower thermosphere retrieved from SOIR on board Venus Express: retrieval technique. J Geophys Res 115:E12014.

Marlow, J.J., LaRowe, D.E., Ehlmann, B.L., Amend, J.P., and Orphan, V.J. (2014) The potential for biologically catalyzed anaerobic methane oxidation on ancient Mars. Astrobiology 14:292-307.

Martin, W. and Russell, M.J. (2007) On the origin of biochemistry at an alkaline hydrothermal vent. Philos Trans $R$ Soc B 362:1887-1926.

Mason, J., Baumgart, M., Woods, T., Hagel, D., Rogler, B., Stafford, G., and Solomon, S. (2016) MinXSS CubeSat onorbit performance and the first flight of the blue canyon technologies XACT 3-axis ADCS. AIAA/Utah State University Small Satellite Conference. Available online at http:// digitalcommons.usu.edu/smallsat/2016/S5GuidCont/2/

McCleese, D.J., Schofield, J.T., Taylor, F.W., Abdou, W.A., Aharonson, O., Banfield, D., Calcutt, S.B., Heavens, N.G., Jirwin, P.G.J., Kass, D.M., Kleinböhl, A., Lawson, W.G., Leovy, C.B., Lewis, S.R., Paige, D.A., Read, P.L., Richardson, M.I., Teanby, N., and Zurek, R.W. (2008) Intense polar temperature inversion in the middle atmosphere on Mars. Nat Geosci 1:745-749.

McCleese, D.J., Schofield, J.T., Taylor, F.W., Abdou, W.A., Aharonson, O., Banfield, D., Calcutt, S.B., Heavens, N.G., Jirwin, P.G.J., Kass, D.M., Kleinböhl, A., Lawson, W.G., Leovy, C.B., Lewis, S.R., Paige, D.A., Read, P.L., Richardson, M.I., Teanby, N., and Zurek, R.W. (2010) The structure and dynamics of the Martian lower and middle atmosphere as observed by the Mars climate sounder: 1 . seasonal variations in zonal mean temperature, dust and water ice aerosols. $J$ Geophys Res 115:E12016. 
McCollom, T.M. and Bach, W. (2009) Thermodynamic constraints on hydrogen generation during serpentinization of ultramafic rocks. Geochim Cosmochim Acta 73:856-875.

McCollom, T.M. and Donaldson, C. (2016) Generation of hydrogen and methane during experimental low-temperature reaction of ultramafic rocks with water. Astrobiology 16:389406.

McCollom, T.M., Sherwood Lollar, B., Lacrampe-Couloume, G., and Seewald, J.S. (2010) The influence of carbon source on abiotic organic synthesis and carbon isotope fractionation under hydrothermal conditions. Geochim Cosmochim Acta 74:2717-2740.

McDunn, T.L., Bougher, S.W., Murphy, J., Smith, M.D., Forget, F., Bertaux, J.-L., and Montmessin, F. (2010) Simulating the density and thermal structure of the middle atmosphere (similar to $80-130 \mathrm{~km}$ ) of Mars using the MGCM-MTGCM: a comparison with MEX/SPICAM observations. Icarus 206: 5-17.

McElroy, M.B., Donahue, T.M. (1972) Stability of the Martian atmosphere. Science 177:986-988.

McSween, H.Y. and Huss, G.R. (2010) Cosmochemistry. Cambridge University Press, Cambridge, United Kingdom.

McSween, H.Y., Taylor, G.J., and Wyatt, M.B. (2009) Elemental composition of the Martian crust. Science 324:736739.

Miller, S.L., 1953. A production of amino acids under possible primitive Earth conditions. Science 117:528-529.

Mitchell, P. (1967) Proton-translocation phosphorylation in mitochondria, chloroplasts and bacteria: natural fuel cells and solar cells. Fed Proc 26:1370-1379.

Mitchell, P. (1975) The protonmotive Q cycle: a general formulation. FEBS Lett 59:137-139.

Mitrofanov, I., Anfimov, D., Kozyrev, A., Litvak, M., Sanin, A., Tret'yakov, V., Krylov, A., Shvetsov, V., Boynton, W., Shinohara, C., Hamara, D., and Saunders, R.S. (2002) Maps of subsurface hydrogen from the high energy Neutron detector, Mars Odyssey. Science 297:78-81.

Mumma, M.J., Villanueva, G.L., Novak, R.E., Hewagama, T., Bonev, B.P., Disanti, M.A., Mandell, A.M., and Smith, M.D. (2009) Strong release of methane on Mars in northern summer 2013. Science 323:1041-1045.

Nair, H., Allen, M., Anbar, A.D., Yung, Y.L., and Clancy, R.T. (1994) A photochemical model of the Martian atmosphere. Icarus 111:124-150.

Nair, H., Summers, M.E., Miller, C.E., and Yung, Y.L. (2005) The isotopic fractionation of methane in the Martian atmosphere. Icarus 175:32-35.

Navarro, T., Forget, F., Millour, E., and Greybush, S.J. (2014a) Detection of detached dust layers in the Mars atmosphere from their thermal signature using assimilation. Geophys Res Lett 41:6620-6626.

Navarro, T., Madeleine, J.B., Forget, F., Spiga, A., Millour, E., Montmessin, F., and Määttänen, A. (2014b). Global climate modeling of the Martian water cycle with improved microphysics and radiatively active water ice clouds. J Geophys Res 119:1479-1495.

Nitschke, W. and Russell, M.J. (2009) Hydrothermal focusing of chemical and chemiosmotic energy, supported by delivery of catalytic $\mathrm{Fe}, \mathrm{Ni}, \mathrm{Mo} / \mathrm{W}, \mathrm{Co}, \mathrm{S}$ and $\mathrm{Se}$, forced life to emerge. J Mol Evol 69:481-496.

Nitschke, W., McGlynn, S.E., Milner-White, E.J., and Russell, M.J. (2013) On the antiquity of metalloenzymes and their substrates in bioenergetics. Biochim Biophys Acta Bioenerg 1827:871-881.
Oehler, D.Z. and Allen, C.C. (2010) Evidence for pervasive mud volcanism in Acidalia Planitia, Mars. Icarus 208:636-657.

Oehler, D.Z. and Etiope, G. (2017) Methane seepage on Mars: where to look and why. Astrobiology 17:1233-1264.

Oehler, D.Z., Allen, C.C., and McKay, D.S. (2005) Impact metamorphism of subsurface organic matter on Mars: a potential source for methane and surface alteration. LPSC XXXVI, Abstract 1025.

Ojha, L., Wilhelm, M., Murchie, S., McEwen, A., Wray, J., Hanley, J., Massé, M., and Chojnacki, M. (2015) Spectral evidence for hydrated salts in recurring slope lineae on Mars. Nat Geosci 8:829-832.

Onstott, T.C., McGown, D., Kessler, J., Lollar, B.S., Lehmann, K.K., and Clifford, S.M. (2006) Martian $\mathrm{CH}_{4}$ : sources, flux, and detection. Astrobiology 6:377-395.

Orosei, R., Lauro, S.E., Pettinelli, E., Cicchetti, A., Coradini, M., Cosciotti, B., Di Paolo, F., Flamini, E., Mattei, E., Pajola, M., Soldovieri, F., Cartacci, M., Cassenti, F., Frigeri, A., Giuppi, S., Martufi, R., Masdea, A., Mitri, G., Nenna, C., Noschese, R., Restano, M., Seu, R. (2018) Radar evidence of subglacial liquid water on Mars. Science doi: 10.1126/science.aar7268.

Oze, C. and Sharma, M., (2005) Have olivine, will gas: serpentinization and the abiogenic production of methane on Mars. Geophys Res Lett 32:L10203.

Planetary Science Decadal Survey: Committee on the Planetary Science Decadal Survey; National Research Council. (2011) Vision and Voyages for Planetary Science in the Decade 2013-2022. National Academy of Sciences, Washington, DC. Ramirez, R.M., Kopparapu, R., Zugger, M.E., Robinson T.D., Freedman, R., and Kasting J.F. (2014) Warming early Mars with $\mathrm{CO}_{2}$ and $\mathrm{H}_{2}$. Nat Geosci 7:59-63.

Richardson, M.I., Toigo, A.D., and Newman, C.E. (2007) PlanetWRF: a general purpose, local to global numerical model for planetary atmospheric and climate dynamics. J Geophys Res 112:E09001.

Rivkina, E.M., Friedmann, E.I., McKay, C.P., and Gilichinsky, D.A. (2000) Metabolic activity of permafrost bacteria below the freezing point. Appl Environ Microbiol 66:3230-3233.

Robert, S., Vandaele, A.C., Thomas, I., Willame, Y., Daerden, F., Delanoye, S., Depiesse, C., Drummond, R., Neefs, E., Neary, L., Ristic, B., Mason, J., Lopez-Moreno, J.-J., Rodriguez-Gomez, J., Patel, M.R., Bellucci, G., and the NOMAD Team. (2016) Expected performances of the NOMAD/ExoMars instrument. Planet Space Sci 124:94-104.

Roos-Serote, M., Atreya, S.K., Webster, C.R., and Mahaffy, P.R. (2016) Cometary origin of atmospheric methane variations on Mars unlikely. J Geophys Res 121:2108-2119.

Rowe, A.R., Chellamuthu, P., Lam, B., Okamoto, A., and Nealson, K.H. (2015) Marine sediments microbes capable of electrode oxidation as a surrogate for lithotrophic insoluble substrate metabolism. Front Microbiol 5:784.

Russell, M.J. (2007) The alkaline solution to the emergence of life: energy, entropy and early evolution. Acta Biotheor 55: 133-179.

Russell, M.J. and Hall, A.J. (1997) The emergence of life from iron monosulphide bubbles at a submarine hydrothermal redox and pH front. J Geol Soc 154:377-402.

Russell, M.J. and Hall, A.J. (2009) The hydrothermal source of energy and materials at the origin of life. In Chemical Evolution II: From the Origins of Life to Modern Society, edited by L. Zaikowski, J.M. Friedrich, and S.R. Seidel, American Chemical Society, Washington, DC.

Russell, M.J., Barge, L.M., Bhartia, R., Bocanegra, D., Bracher, P.J., Branscomb, E., Kidd, R., McGlynn, S., Meier, D.H., 
Nitschke, W., Shibuya, T., Vance, S., White, L., and Kanik, I. (2014) The drive to life on wet and icy worlds. Astrobiology 14:308-343.

Schoepp-Cothenet, B., van Lis, R., Philippot, P., Magalon, A., Russell, M.J., and Nitschke, W. (2012) The ineluctable requirementfor the trans-iron elements molybdenum and/or tungsten in the origin of life. Sci Rep 2:263.

Seewald, J.S., Zolotov, M.Y., and McCollom, T. (2006) Experimental investigation of single carbon compounds under hydrothermal conditions. Geochim Cosmochim Acta 70:446460.

Sherwood Lollar, B., Westgate, T., Ward, J., Slater, G.F., and Lacrampe-Couloume, G. (2002) Abiogenic formation of alkanes in the Earth's crust as a minor source for global hydrocarbon reservoirs. Nature 416:522-524.

Sherwood Lollar, B., Lacrampe-Couloume, G., Slater, G.F., Ward, J., Moser, D.P., Gihring, T.M., Lin, L.-H., and Onstott, T.C. (2006) Unravelling abiogenic and biogenic sources of methane in the Earth's deep subsurface. Chem Geol 226:328339.

Sherwood Lollar, B., Onstott, T.C., Lacrampe-Couloume, G., and Ballentine, C.J. (2014) The contribution of the Precambrian continental lithosphere to global $\mathrm{H}_{2}$ production. Nature 516:379-382.

Shock, E.L. (1992) Chemical environments of submarine hydrothermal systems. Origins Life Evol Biosphere 22:67-107.

Sindoni, G., Formisano, V., and Geminale, A. (2011) Observations of water vapour and carbon monoxide in the Martian atmosphere with the SWC of PFS/MEX. Planet Space Sci 59: 149-162.

Sleep, N.H. and Zoback, M.D. (2007) Did earthquakes keep the early crust habitable? Astrobiology 7:1023-1032.

Smith, E. and Morowitz, H. J. (2016) The Origin and Nature of Life on Earth: The Emergence of the Fourth Geosphere. Cambridge: Cambridge University Press.

Smith, M.D., Wolff, M.J., Clancy R.T., and Murchie, S.L. (2009) Compact reconnaissance imaging spectrometer observations of water vapor and carbon monoxide. J Geophys Res 114:E00D03.

Sonnabend, G., Sornig, M., Krötz, P.J., Schieder, R.T., and Fast, K.E. (2006) High spatial resolution mapping of Mars mesospheric zonal winds by infrared heterodyne spectroscopy of $\mathrm{CO}_{2}$. Geophys Res Lett 33:L18201.

Spiga, A., Faure, J., Madeleine, J.-B., Määttänen, A., and Forget, F. (2013) Rocket dust storms and detached dust layers in the Martian atmosphere. J Geophys Res 118:746767.

Staehle, R.L., Spangelo, S, Eby, M, Lane, M.S., Aaron, K.M., Bhartia, R, Boland, J.S., Christiansen, L.E., Forouhar, S., de la Torre Juarez, M., Paige, D.A., Trawny, N., Webster, C.R., and Williams, R.M.E. (2015) Multiplying

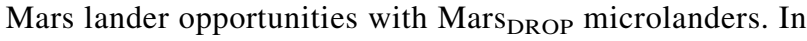
AIAA/USU Small Satellite Conference SSC15-XI-3, Logan, Utah.

Steele, L.J., Lewis, S.R., and Patel, M.R. (2014) The radiative impact of water ice clouds from a reanalysis of Mars climate sounder data. Geophys Res Lett 41:4471-4478.

Stüeken, E.E., Anderson, R.E., Bowman, J.S., Brazelton, W.J., Colangelo-Lillis, J., Goldman, A.D., Som, S.M., and Baross, J.A. (2013) Did life originate from a global chemical reactor? Geobiology 11:101-126.

Stuurman, C.M., Osinski, G.R., Holt, J.W., Levy, J.S., Brothers, T.C., Kerrigan, M., and Campbell, B.A. (2016) SHARAD detection and characterization of subsurface water ice de- posits in Utopia Planitia, Mars. Geophys Res Lett 43:94849491.

Summers, M.E., Lieb, B.J., Chapman, E., and Yung, Y.L. (2002) Atmospheric biomarkers of subsurface life on Mars. Geophys Res Lett 29:2171-2174.

Takai, K., Nakamura, K., Toki, T., Tsunogai, U., Miyazaki, M., Miyazaki, J., Hirayama, H., Nakagawa, S., Nunoura, T., and Horikoshi, K. (2008) Cell proliferation at $122^{\circ} \mathrm{C}$ and isotopically heavy $\mathrm{CH}_{4}$ production by a hyperthermophilic methanogen under high-pressure cultivation. Proc Natl Acad Sci U S A 105:10949-10954.

Toigo, A.D., Lee, C., Newman, C.E., and Richardson, M.I. (2012), The impact of resolution on the dynamics of the Martian global atmosphere: varying resolution studies with the MarsWRF GCM. Icarus 221:276-288.

Tokar, R., Feldman, W., Prettyman, T., Moore, K., Lawrence, D., Elphic, R., Kreslavsky, M., Head, J., Mustard, J., and Boynton, W. (2002) Ice concentration and distribution near the south pole of Mars: synthesis of odyssey and global surveyor analyses. Geophys Res Lett 29:1904.

Tschimmel, M., Ignatiev, N.I., Titov, D.V., Lellouch, E., Fouchet, T., Gluranna, M., and Formisano, V. (2008) Investigation of water vapor on Mars with PFS/SW of Mars express. Icarus 195:557-575.

Vandaele, A.C., Neefs, E., Drummond, R., Thomas, I.R., Daerden, F., Lopez-Moreno, J.-J., Rodriguez, J., Patel, M.R., Bellucci, G., Allen, M., Altieri, F., Bolsée, D., Clancy, T., Delanoye, S., Depiesse, C., Cloutis, E., Fedorova, A., Formisano, V., Funke, B., Fussen, D., Geminale, A., Gérard, J.-C., Giuranna, M., Ignatiev, N., Kaminski, J., Karatekin, O., Lefèvre, F., López-Puertas, M., López-Valverde, M., Mahieux, A., McConnell, J., Mumma, M., Neary, L., Renotte, E., Ristic, B., Robert, S., Smith, M., Trokhimovsky, S., Vander Auwera, J., Villanueva, G., Whiteway, J., Wilquet, V., Wolff, M., and the NOMAD Team. (2015) Science objectives and performances of NOMAD, a spectrometer suite for the ExoMars TGO mission. Planet Space Sci 119:233-249.

Webster, C.R., Mahaffy, P.R., Atreya, S.K., Flesch, G.J., Farley, K.A., and the MSL Science Team. (2013) Low upper limit to methane abundance on Mars. Science 342:355-357.

Webster, C.R., Mahaffy, P.R., Atreya, S.K., Flesch, G.J., Mischna, M.A., Meslin, P.Y., Farley, K.A., Conrad, P.G., Christensen, L.E., Pavlov, A.A., Martín-Torres, J., Zorzano, M.P., McConnochie, T.H., Owen, T., Eigenbrode, J.L., Glavin, D.P., Steele, A., Malespin, C.A., Archer, P.D., Jr., Sutter, B., Coll, P., Freissinet, C., McKay, C.P., Moores, J.E., Schwenzer, S.P., Bridges, J.C., Navarro-Gonzalez, R., Gellert, R., Lemmon, M.T., and the MSL Science Team. (2015) Mars methane detection and variability at Gale crater. Science 347:415-417.

Webster, C.R., Mahaffy, P.R., Atreya, S.K., Moores, J.E., Flesch, G.J., Malespin, C., McKay, C.P., Martinez, G., Smith, C.L., Martin-Torres, J., Gomez-Elvira, J., Zorzano, M.P., Wong, M.H., Trainer, M.G., Steele, A., Archer, D., Sutter, B., Coll, P.J., Freissinet, C., Meslin, P-Y, Gough, R.V., House, C.H., Pavlov, A, Eigenbrode, J.L., Glavin, D.P., Pearson, J.C., Keymeulen, D., Christensen, L.E., Schwenzer, S.P., Navarro-Gonzalez, R., Pla-Garćia, J., Rafkin, S.C.R., Vicente-Retortillo, Á, Kahanpää, H., Viudez-Moreiras, D., Smith, M.D., Harri, A-M, Genzer, M., Hassler, D.M., Lemmon, M., Crisp, J., Sander, S.P., Zurek, R.W., and Vasavada, A.R. (2018) Background levels of methane in Mrs' atmosphere show strong seasonal variations. Science 360:1093-1096. 
Weiss, B.P., Yung, Y.L., and Nealson, K.H. (2000) Atmospheric energy limits on subsurface life on Mars? Proc Natl Acad Sci U S A 97:1395-1399.

Westheimer, F.H. (1987) Why nature chose phosphates. Science 235:1173-1178.

Wilson, R.J. and Hamilton, K. (1996) Comprehensive model simulation of thermal tides in the Martian atmosphere. $J$ Atmos Sci 53:1290-1326.

Withers, P. and Smith, M.D. (2006) Atmospheric entry profiles from the Mars Exploration Rovers Spirit and Opportunity. Icarus 185:133-142.

Wordsworth, R. (2016) The climate of early Mars. Annu Rev Earth Planet Sci 44:381-408.

Wordsworth, R., Kalugina, Y., Lokshtanov, S., Vigasin, A., Ehlmann, B., Head, J., Sanders, C., and Wang, H. (2017) Transient reducing greenhouse warming on early Mars. Geophys Res Lett 44:665-671.

Wray, J.J. and Ehlmann, B.L. (2011) Geology of possible Martian methane source regions. Planet Space Sci 59:196-202.

Xia, D., Esser, L., Yu, L., and Yu, C.A. (2007) Structural basis for the mechanism of electron bifurcation at the quinol oxidation site of the cytochrome bc1 complex. Photosynth Res 92:17-34.

Yung, Y.L. and Chen, P. (2015) Methane on Mars. J Astrobiol Outreach 3:125.

Yung, Y.L. and DeMore, W.B. (1999) Photochemistry of Planetary Atmospheres, Oxford University Press, New York, NY.

Yung, Y.L., Russell, M.J., and Parkinson, C.D. (2010) The search for life on Mars. J Cosmol 5:1121-1130.

Zahnle, K., Freedman, R.S., and Catling, D. (2011) Is there methane on Mars? Icarus 212:493-503.
Address correspondence to: Pin Chen

Science Division

NASA Jet Propulsion Laboratory

California Institute of Technology

M/S 183-301, 4800 Oak Grove Drive

Pasadena, CA 91109

E-mail: pin.chen@jpl.nasa.gov

Submitted 7 June 2018

Accepted 12 June 2018

$\begin{aligned} & \text { Abbreviations Used } \\ & \mathrm{ACS}=\text { Atmospheric Chemistry Suite } \\ & \mathrm{CH}_{4}=\text { methane } \\ & \mathrm{FTT}=\text { Fischer-Tropsch type } \\ & \mathrm{GCM}=\text { general circulation model } \\ & \mathrm{LMD}=\text { Laboratoire de Météorologie Dynamique } \\ & \mathrm{MEX}=\text { Mars Express } \\ & \mathrm{MGCM}=\text { Mars general circulation models } \\ & \mathrm{MSL}=\text { Mars Science Laboratory } \\ & \mathrm{NOMAD}=\text { Nadir and Occultation for Mars Discovery } \\ & \mathrm{PIC}=\text { photonic-integrated-circuit } \\ & \mathrm{ppbv}=\text { parts per billion by volume } \\ & \mathrm{SAM}=\text { Sample Analysis at Mars } \\ & \mathrm{TGO}=\text { Trace Gas Orbiter } \\ & \mathrm{TLS}=\text { Tunable Laser Spectrometer } \\ &\end{aligned}$

\section{Appendix 1}

\section{A Synopsis of Non-TLS-MSL Mars Methane Measurements}

Ground-based telescopic and Mars Express (MEX) orbital observations of $\mathrm{CH}_{4}$ on Mars have been extremely interesting, but remain tentative.

The first reports of $\mathrm{CH}_{4}$ in Mars' atmosphere, by both MEX and ground-based observations (at 10 parts per billion by volume [ppbv] level), stirred up excitement in the scientific community (Formisano et al., 2004; Krasnopolsky et al., 2004) and immediately raised questions regarding the origin of that $\mathrm{CH}_{4}$. On Mars, oxidants and UV radiation readily destroy atmospheric methane. Therefore, the presence of atmospheric $\mathrm{CH}_{4}$ requires ongoing or recent emission. On Earth, $\mathrm{CH}_{4}$ is predominantly of (live and fossil) biological origin, while abiotic sources, believed to be predominantly volcanic and/or hydrothermal (both hightemperature and low-temperature water/rock reaction hydrothermal processes), account for the rest (a few percent) of the total $\mathrm{CH}_{4}$ flux into the atmosphere (Etiope and Sherwood Lollar, 2013). The observations of $\mathrm{CH}_{4}$ in Mars' atmosphere turn the theoretical musings of possible life on Mars into a necessary investigative component for inter- preting observational data. The findings elevate the possibility of hydrothermal activity on Mars, which could furnish habitable environments by providing liquid water and redox energy to sustain life. Moreover, these findings compel new research directions to explore novel processes that can produce $\mathrm{CH}_{4}$ on Mars and revise our understanding of the basic physical, chemical, and geological processes taking place on the planet.

Subsequent to 2004, several teams reported high spatial and temporal variability, including plumes of up to $60 \mathrm{ppbv}$ $\mathrm{CH}_{4}$. This variability posed an even greater theoretical challenge than the mere presence of $\mathrm{CH}_{4}$. Methane's predicted 300-year atmospheric lifetime is far longer than the global mixing time of about 1 month (Lefèvre and Forget, 2009; Mumma et al., 2009; Fonti and Marzo, 2010; Geminale et al., 2011). Hence, $\mathrm{CH}_{4}$ should be uniformly distributed in the martian atmosphere. Introducing novel, much more efficient sinks can shorten the predicted lifetime of methane (Atreya et al., 2006). However, a strong sink, whatever its nature, would also require a source that seems implausibly strong. Indeed, Lefèvre and Forget (2009) stated that the observed variations of $\mathrm{CH}_{4}$ on Mars are not explained by standard models of atmospheric chemistry and 
physics. Previous remote-sensing detection claims have been called into question due to interference from telluric absorption in the ground-based observations, low spectral resolution in the orbital observations, and contradictions between the locations of maxima reported from groundbased observations and maps obtained by the Planetary Fourier Spectrometer and Thermal Emission Spectrometer (Lefèvre and Forget, 2009; Zahnle et al., 2011; Kerr, 2012).
Given the puzzling nature of observations of $\mathrm{CH}_{4}$ on Mars, it is highly desirable to obtain simultaneous measurements over specific locations using more than one instrument, for example, Mars Science Laboratory (MSL)Tunable Laser Spectrometer (TLS) and ground-based observations, or MSL-TLS and Trace Gas Orbiter. We consider the confirmation of $\mathrm{CH}_{4}$ by two independent observations a high priority for the future exploration of Mars. 